\title{
Clinical and Technical Guideline for Endoscopic Ultrasound (EUS)-Guided Tissue Acquisition of Pancreatic Solid Tumor: Korean Society of Gastrointestinal Endoscopy (KSGE)
}

\begin{abstract}
Moon Jae Chung ${ }^{1}$, Se Woo Park ${ }^{2}$, Seong-Hun Kim³ ${ }^{3}$ Chang Min Cho ${ }^{4}$, Jun-Ho Choi ${ }^{5}$, Eun Kwang Choi ${ }^{6}$, Tae Hoon $\mathrm{Lee}^{7}$, Eunae Cho ${ }^{8}$, Jun Kyu Lee ${ }^{9}$, Tae Jun Song ${ }^{10}$, Jae Min Lee ${ }^{11}$, Jun Hyuk Son ${ }^{12}$, Jin Suk Park ${ }^{13}$, Chi Hyuk Oh ${ }^{14}$, Dong-Ah Park ${ }^{15}$, Jeong-Sik Byeon ${ }^{10}$, Soo Teik Lee ${ }^{3}$, Ho Gak Kim ${ }^{16}$, Hoon Jai Chun ${ }^{11}$, Ho Soon Choi ${ }^{17}$, Chan Guk Park ${ }^{18}$, and Joo Young Cho ${ }^{19}$

${ }^{1}$ Division of Gastroenterology, Department of Internal Medicine, Severance Hospital, Yonsei University College of Medicine, Seoul, ${ }^{2}$ Division of Gastroenterology, Department of Internal Medicine, Hallym University College of Medicine, Hwaseong, ${ }^{3}$ Department of Internal Medicine, Research Institute of Clinical Medicine of Jeonbuk National University-Biomedical Research Institute of Jeonbuk National University Hospital, Jeonju, ${ }^{4}$ Department of Internal Medicine, School of Medicine, Kyungpook National University, Daegu, ${ }^{5}$ Division of Gastroenterology, Department of Internal Medicine, Dankook University College of Medicine, Cheonan, ${ }^{6}$ Division of Gastroenterology, Department of Internal Medicine, Jeju National University College of Medicine, Jeju, ${ }^{2}$ Division of Gastroenterology, Department of Internal Medicine, Soonchunhyang University College of Medicine, Cheonan, ${ }^{8}$ Division of Gastroenterology, Department of Internal Medicine, Chonnam National University College of Medicine, Gwangju, 9 Division of Gastroenterology, Department of Internal Medicine, Dongguk University College of Medicine, Goyang, ${ }^{10}$ Division of Gastroenterology, Department of Internal Medicine, University of Ulsan College of Medicine, ${ }^{11}$ Division of Gastroenterology, Department of Internal Medicine, Korea University College of Medicine, Seoul, ${ }^{2}$ Division of Gastroenterology, Department of Internal Medicine, Inje University College of Medicine, Busan, ${ }^{13}$ Division of Gastroenterology, Department of Internal Medicine, Inha University College of Medicine, Incheon, ${ }^{14}$ Division of Gastroenterology, Department of Internal Medicine, Kyung Hee University College of Medicine, ${ }^{15}$ Division of Healthcare Technology Assessment Research, Office of Health Technology Assessment Research, National Evidence-Based Healthcare Collaborating Agency, Seoul, ${ }^{16}$ Division of Gastroenterology, Department of Internal Medicine, Daegu Catholic University School of Medicine, Daegu, ${ }^{17}$ Division of Gastroenterology, Department of Internal Medicine, Hanyang University College of Medicine, Seoul, ${ }^{18}$ Division of Gastroenterology, Department of Internal Medicine, Chosun University College of Medicine, Gwangju, and ${ }^{19}$ Division of Gastroenterology, Department of Internal Medicine, Cha University College of Medicine, Seongnam, Korea
\end{abstract}

\section{Article Info}

Received October 5, 2020

Revised December 13, 2020

Accepted January 15, 2021

Published online March 26, 2021

Corresponding Author

Se Woo Park

ORCID https://orcid.org/0000-0003-1603-7468

E-mail britnepak@hallym.or.kr
Endoscopic ultrasound (EUS)-guided tissue acquisition of pancreatic solid tumor requires a strict recommendation for its proper use in clinical practice because of its technical difficulty and invasiveness. The Korean Society of Gastrointestinal Endoscopy (KSGE) appointed a task force to draft clinical practice guidelines for EUS-guided tissue acquisition of pancreatic solid tumor. The strength of recommendation and the level of evidence for each statement were graded according to the Minds Handbook for Clinical Practice Guideline Development 2014. The committee, comprising a development panel of 16 endosonographers and an expert on guideline development methodology, developed 12 evidence-based recommendations in eight categories intended to help physicians make evidence-based clinical judgments with regard to the diagnosis of pancreatic solid tumor. This clinical practice guideline discusses EUS-guided sampling in pancreatic solid tumor and makes recommendations on circumstances that warrant its use, technical issues related to maximizing the diagnostic yield (e.g., needle type, needle diameter, adequate number of needle passes, sample obtaining techniques, and methods of specimen processing), adverse events of EUS-guided tissue acquisition, and learning-related issues. This guideline was reviewed by external experts and suggests best practices recommended based on the evidence available at the time of preparation. This guideline may not be applicable for all clinical situations and should be interpreted in light of specific situations and the availability of resources. It will be revised as necessary to cover progress and changes in technology and evidence from clinical practice. (Gut Liver 2021;15:354-374)

Key Words: Endoscopic ultrasound; Pancreatic solid tumor; Tissue; Technique; Guideline 


\section{INTRODUCTION}

Endoscopic ultrasound (EUS)-guided fine-needle aspiration (FNA) plays an essential role in the establishment of an accurate tissue diagnosis and tailored treatment plan for pancreatic solid tumors, and is associated with few major adverse events. ${ }^{1}$ Diagnosis based on EUS-FNA has relatively high but widely variable sensitivity and specificity $(75 \%$ to $92 \%$ and $82 \%$ to $100 \%$, respectively), with a diagnostic accuracy and adverse events rate ranging from $70 \%$ to $100 \%$ and from $0 \%$ to $3 \%$, respectively. ${ }^{2-4}$ With the recent introduction of EUS-guided fine needle biopsy (FNB), histological analysis now allows for the differential diagnosis of various pancreatic solid tumors. In the current personalized medicine era, it is becoming increasingly essential to obtain optimal histologic core for molecular analysis. ${ }^{5}$ Despite these advances in tissue acquisition of pancreatic solid tumors, many aspects still require clinical and technical standardization. This clinical and technical practice guideline for EUS-guided tissue acquisition of pancreatic solid tumor includes recommendations on circumstances that warrant its use, the technique for obtaining the highest possible yield, sample processing method, adverse events related to the procedure, and the learning curve of the average trainee.

Our purpose was to establish a practical guideline for EUS-guided tissue acquisition that applies to the current medical practice. The target for this guideline includes patients with pancreatic solid tumor requiring tissue diagnostic confirmation. We aimed to provide a suitable framework for making decisions regarding the appropriate and accurate diagnosis for preoperative evaluation and postoperative management of patients with pancreatic solid tumors. The target audience for this guideline includes cli- nicians who perform EUS-guided tissue acquisition ranging from general clinicians to physicians that specialize in pancreatology, clinical researchers, and health policymakers involved in the diagnosis and treatment of pancreatic solid tumors. A summary of the evidence statement and recommendations is provided at the end of this paper.

\section{MATERIALS AND METHODS}

\section{Formation of committee members and stakeholder involvement}

The Korean Society of Gastrointestinal Endoscopy (KSGE) Task Force on Guideline for EUS-guided tissue acquisition of pancreatic solid tumor comprised a development panel of 16 endosonographers, who were experts in this field, and an expert in methodology for guideline development. Conflicts of interest were disclosed according to the guideline of the KSGE. During the development of this guideline, no members of the Task Force were solicited or asked about the development activities by other stakeholders. There was also an internal evaluation panel within members of the committee comprising six gastroenterologists, one pathologist, and one statistician in charge of methodology for guideline development. Six external validation panel members were also asked to conduct a full evaluation (Table 1). Then, the guidelines were evaluated and validated by a wide range of additional external experts, including the epidemiologist, health care provider, clinical physicians, and surgeons.

\section{Selection of key questions}

The members of the committee set up the following eight items: indication of EUS-guided tissue acquisition

Table 1. Task Force Team for the Guidelines for EUS-Guided Tissue Acquisition from Solid Pancreatic Tumors

\begin{tabular}{ll}
\hline $\begin{array}{l}\text { KSGE Clinical Practice Guideline Committee } \\
\text { President }\end{array}$ & Hoon Jai Chun (in November 2017) \\
& Joo Young Cho (present) \\
& Soo Teik Lee (in November 2017) \\
Congress chairman & Ho Gak Kim (in November 2018) \\
& Chan Guk Park (present) \\
& Jeong-Sik Byeon \\
Director and chairperson of the KSGE Task Force & \multicolumn{1}{c}{ Se Woo Park } \\
KSGE Task Force on Clinical Practice Guideline for EUS-guided tissue acquisition of pancreatic solid tumor \\
Director & Se Woo Park, Moon Jae Chung \\
Development panel director & Seong-Hun Kim, Chang Min Cho, Jun-Ho Choi, Eun Kwang Choi, Tae Hoon Lee, Eunae Cho \\
Development panel members & Jun Kyu Lee \\
Evaluation panel director & Tae Jun Song, Jae Min Lee, Jun Hyuk Son, Jin Suk Park, Chi Hyuk Oh \\
Evaluation panel members & Dong-Ah Park and her team \\
External evaluation panel members & The Korean Society of Gastroenterology \\
Collaborating societies & Korean Pancreatobiliary Association \\
&
\end{tabular}

KSGE, Korean Society of Gastrointestinal Endoscopy; EUS, endoscopic ultrasound. 
of pancreatic solid tumor; selection of the appropriate needle; the optimal number of needle passes; strategy for inadequate or inconclusive pathological results; specific endoscopic techniques; methods of specimen processing; adverse events and their prevention; and learning-related issues. Because the definition of pancreatic solid tumor and the significance of diagnosing pancreatic solid tumor by image modalities represents the major premise on which this guideline is formulated, we did not handle this item as a statement. Therefore, key questions (KQs) were prepared for the other eight items, and modifications were made based on opinions of the internal evaluation panel such that there were 12 statements in total. The KQs were established through the PICO process; P (population) represents patients with pancreatic solid tumors; I (intervention) represents main therapeutic interventions including EUS-guided tissue acquisition; C (comparison) represents main alternative therapeutic interventions to compare with the interventions; and $\mathrm{O}$ (outcome) represents the usefulness of diagnostic performance.

\section{Literature search and selection}

For each KQ, a systematic literature search was conducted until December 2017 using PubMed and the Cochrane database. A detailed description of keywords and search formulas were given for each statement. In addition, a manual search was conducted when there were insufficient research results to refer to. The literature search was performed by members of the team of experts for clinical practice guideline development who suggested search queries and presented search results in collaboration with the committee members. We searched the Cochrane Library, EMBASE, KoreaMed, MEDLINE, and the Guideline International Network in July 2019. Keywords related to the pancreatic solid tumor (" "pancreatic" OR "pancreas" OR "pancreato") AND ("cancer" OR "tumor" OR "carcinoma" OR "adenocarcinoma" OR "neoplasm")), and endoscopic ultrasound (EUS)-guided tissue acquisition (("endoscopic ultrasound" OR "EUS" OR "Echoendoscopic") AND ("aspiration" OR "biopsy" OR "histologic" OR "pathologic" OR "cytologic")) were used. Different keywords or different combinations of keywords were also used based on each KQ.

The exclusion criteria were as follows: (1) studies not involving human subjects or the target populations of the guideline's KQs; (2) studies that did not perform an intervention related to the KQs and intervention for comparison; (3) studies that were case reports, unpublished studies, abstract-only publications, or review articles; (4) studies that were published in a language other than English; and (5) the original full-text could not be found. In the first stage of study selection, duplicate studies were removed. For each $\mathrm{KQ}$, titles and abstracts of articles returned from our keyword search were examined independently by two assigned committee members to exclude irrelevant articles. The entire contents of all selected full-texts were then screened as per our inclusion and exclusion criteria. ${ }^{6}$ Two independent investigators for each KQ evaluated the studies for eligibility and resolved any disagreements through discussion and consensus. When no agreement could be reached, the team leader (S.W.P) of the corresponding subcommittee made the final conclusion. Moreover, additional research was undertaken to identify extra studies through the references of the screened articles. The last date of updating our search was March 31, 2020.

\section{Evidence assessment and formulating recommendations}

Qualitative systematic reviews were conducted to evaluate the risk of biases and heterogeneity of each study. The domains of risk of bias included performance bias, selection bias, attrition bias, detection bias, and other biases. The revised Cochrane risk of bias tool was used to evaluate randomized controlled trials (RCTs), ${ }^{6,7}$ and the NewcastleOttawa assessment scale was used to evaluate nonrandomized studies. ${ }^{6,8}$ The Quality Assessment of Diagnostic Accuracy Studies (QUADAS)-2 tool was used for the study of diagnostic test accuracy. ${ }^{9}$ The members of the committee determined the level of evidence for each study within their allocated field, and the strength of recommendation and level of evidence for each statement were determined according to the Minds Handbook for Clinical Practice Guideline Development 2014.

The strength of recommendations was graded with reference to (1) the quality of the evidence, (2) the homogeneity of the study population, (3) risks-benefits analysis, and (4) cost analysis. Regarding consensus establishment, a total of 12 committee members voted for each proposed statement according to the modified Delphi method, which uses a scoring system (sum of the score 1-2: nonconsensus, 3: dissatisfaction, 4-5: consensus). The options were adopted as confirmative statements if any of the statements achieve a consensus of $2 / 3$ agreement or higher as agree or agree strongly (as point 4 or 5). If the proposed statements had an agreement $<2 / 3$ among 12 committee members, either it had to be modified or the strength of recommendation had to be amended through discussion within the committee; subsequently, voting was repeated until a higher agreement above 2/3 was achieved. According to the sum of the score, the grading of recommendations was divided into two categories, "1: Strong Recommendations" and "2: Weak Recommendations," which are 
described as "recommendations" and "suggestions," respectively. ${ }^{10,11}$ Table 2 summarizes the recommendations with their grades of recommendation and levels of evidence.

\section{Review and approval}

For an internal review by the KSGE, a total of 34 members of the KSGE Steering Committee and 14 members from the Insurance Committee of KSGE reviewed the first draft using open questions and provided comments. The draft was revised according to the comments to ensure balance and completeness of the guideline. Furthermore, for an external review of the guideline, a modified e-Delphi mechanism process such as employing the online platform was then used for 11 expert panels to produce an evidence-

Table 2. Summary and Strength of Recommendations for EUS-Guided Tissue Acquisition from Solid Pancreatic Tumors

Statement 1: Tissue confirmation is strongly recommended in patients with solid pancreatic tumor who will undergo anti-tumor therapy such as chemotherapy or radiotherapy at the unresectable stage, including metastatic or locally advanced lesions (level of evidence: high, grade of recommendation: strong). Furthermore, tissue confirmation is also recommended at the resectable stage to exclude benign disease before surgical resection and minimize unnecessary surgeries. In addition, tissue confirmation is preferred at the borderline resectable stage for determination of appropriate neoadjuvant therapy. It may be mandatory in certain circumstances in which it is difficult to definitively diagnosis between malignancy and unusual tumors (e.g., lymphoma, some pancreatic metastases, or autoimmune pancreatitis) (level of evidence: moderate, grade of recommendation: weak).

\section{Statement 2:}

2-1. For routine EUS-guided tissue acquisition of pancreatic solid tumors, FNA and FNB needles are equally recommended. When the primary aim of sampling is to obtain a histologic core tissue specimen (e.g., focal autoimmune pancreatitis or neuroendocrine tumors), KSGE recommends using FNB needles (level of evidence: moderate, grade of recommendation: strong).

2-2. Our group suggests that no specific type or diameter of needle has a higher diagnostic accuracy than others in EUS-guided tissue acquisition for solid pancreatic tumors. However, 22-gauge needles tended to have superior outcomes compared to 19-gauge or 25-gauge needles in terms of optimal histologic core procurement and sample adequacy (level of evidence: low, grade of recommendation: weak).

Statement 3: Because ROSE is not available in Korea, our group suggests that 4 needle passes using EUS-guided tissue acquisition may be adequate to achieve appropriate diagnosis in patients with pancreatic tumors. Pancreatic tumors less than $2 \mathrm{~cm}$ may require a higher number of needle passes. Furthermore, fewer needle passes might be required for the EUS-FNB procedure llevel of evidence: low, grade of recommendation: weak).

Statement 4: Repeat EUS-guided acquisition provides a conclusive diagnosis in the majority of cases with indeterminate cytopathological diagnoses and, therefore, should be strongly recommended ahead of other modalities such as biopsy under CT-guidance or diagnostic surgical exploration (level of evidence: moderate, grade of recommendation: strong). Furthermore, K-ras mutation allows increasing diagnostic accuracy for inconclusive samples (level of evidence: low, grade of recommendation: weak).

Statement 5:

5-1. Our group suggests that routine application of ROSE cannot guarantee an improvement in diagnostic accuracy and performance in terms of sensitivity and specificity. Nevertheless, application of ROSE is expected to achieve higher per-case accuracy than non-application (level of evidence: low, grade of recommendation: weak).

5-2. The use of a stylet during EUS-guided tissue acquisition does not appear to guarantee any advantages with regards to the adequacy of the specimen, diagnostic yield, nor regarding prevention of needle clogging by gut wall tissue llevel of evidence: moderate, grade of recommendation: weak).

5-3. Our group suggests that routine application of suction is recommended in cases where cellularity is poor, such as fibrotic lesions in chronic pancreatitis, whereas it is discouraged in non-fibrotic lesions which may contain necrosis and blood to minimize contamination of the cellular sample (level of evidence: moderate, grade of recommendation: weak). Also, the slow-pull-back technique may be more effective in terms of adequate tissue acquisition and require fewer needle passes for solid pancreatic tumors (level of evidence: low, grade of recommendation: weak).

5-4. Our group suggests that the fanning technique for EUS-guided tissue acquisition offers technically acceptable feasibility and superior diagnostic performance, including fewer needle passes required to establish the definite diagnosis, than the standard technique (level of evidence: moderate, grade of recommendation: strong). Furthermore, the torque technique, similar to the fanning technique, also showed better outcomes regarding optimal histologic core procurement and diagnostic accuracy in comparison with the standard technique (level of evidence: low, grade of recommendation: weak).

Statement 6: Diagnostic performances are most affected by preparations processing (direct smear, liquid-based cytology, cell block, and histology) and by staining techniques (Papanicolaou methods, Diff-Quik, hematoxylin and eosin, and Giemsa). Furthermore, specialized immunohistochemistry staining aids in the diagnosis of epithelial components with cytologic atypia and in differentiating various tumor cell types. The use of immunohistochemistry staining and molecular/genetic assays can enhance the value of oncological predictions and lead to tailormade treatments (level of evidence: low, grade of recommendation: weak).

Statement 7: EUS-guided tissue acquisition is a safe intervention with relatively low risks of mortality $(0.02 \%)$ and morbidity (0.98\%). Procedure-related abdominal pain and post-procedure pancreatitis are the most common adverse events. Most unpredictable adverse events are mild in severity and self-limiting, while severe adverse events are very rare (level of evidence: moderate, grade of recommendation: strong).

Statement 8: In regard to EUS, the average trainee has to perform at least 225 EUS examinations with a total of 50 EUS-guided tissue acquisition procedures for achievement of competency in EUS-guided FNA or FNB (level of evidence: low, grade of recommendation: weak).

EUS, endoscopic ultrasound; FNA, fine-needle aspiration; FNB, fine needle biopsy; KSGE, Korean Society of Gastrointestinal Endoscopy; ROSE, rapid on-site evaluation; $\mathrm{CT}$, computed tomography. 
based consensus. This consensus consisted of two main rounds of web-based voting, using a custom-built online voting platform scoring each using a 5-point scale with updated iterations of the statements and evaluative text based on feedback after each round. Following the first round of voting, the statements that achieved a consensus of $2 / 3$ agreement or higher as agree or agree strongly (as point 4 or 5) were accepted as final statements and recommendations. The statements that did not achieve $2 / 3$ were entered into the second round of voting after appropriate revision based on discussions during the e-Delphi mechanism process. The statements and recommendations that did not reach the $2 / 3$ consensus agreement following two rounds of voting were removed.

\section{Provision of the guideline and plans for next updates}

For universal provision and distribution of the practical guideline, we plan to publish the guideline in Clinical Endoscopy, the Korean Journal of Gastroenterology, the Korean Journal of Pancreas and Biliary Tract, and Gut and Liver. We will also upload the guideline on the website of KSGE and submit it to the Korean Medical Guideline Information Center. Because the rapid distribution of this guideline to endosonographers through the databases is expected to be difficult, the KSGE will distribute the guideline for free via various routes including emails, and will actively promote it in academic conferences, seminars, and workshops. Current recommendations in the practical guideline are based on up to date research and will be revised regularly with new evidence related to technical and instrumental advances, with the KSGE Guideline Committee taking a key role.

\section{Limitations and legal matters}

It is not anticipated that treatment decisions will be made using this practical guideline without first considering the specific conditions of individual patients. Medical conditions such as demographic background, underlying comorbidities, clinical stage, and economic environment vary among individuals. Furthermore, this guideline is not intended to establish an absolute diagnostic or therapeutic standard that physicians should use to manage patients in real clinical settings but aims to assist physicians in making evidence-based clinical judgments with regard to the diagnosis of pancreatic solid tumor. It is impossible for the guideline development committee to consider the specific conditions of each individual patient when formulating recommendations. Thus, this practical guideline should not be used to support legal judgments in the assessment of the appropriateness of individual medical practice.

\section{STATEMENTS}

\section{The indications for EUS-guided tissue acquisition in pancreatic solid tumor: when to puncture?}

\section{Recommendation}

Tissue confirmation is strongly recommended in patients with solid pancreatic tumors who will undergo anti-tumor therapy such as chemotherapy or radiotherapy at the unresectable tumors, including metastatic or locally advanced lesions (level of evidence: high, grade of recommendation: strong). Furthermore, tissue confirmation is also recommended at the resectable tumors to exclude benign disease before surgical resection and minimize unnecessary surgeries. In addition, tissue confirmation is preferred at the borderline resectable stage for the determination of appropriate neoadjuvant therapy. It may be mandatory in certain circumstances in which it is difficult to definitively diagnose between pancreatic ductal adenocarcinoma and unusual tumors (e.g., lymphoma, some pancreatic metastases, or autoimmune pancreatitis) (level of evidence: moderate, grade of recommendation: weak).

It is essential that the indications for EUS-guided tissue acquisition can provide information on the potential treatment strategy of patients with pancreatic solid tumor. Furthermore, endoscopists should consider the technical feasibility in terms of the distance from the echoendoscope to the target lesion as well as blood vessel location during needle puncture. In some countries, tissue confirmation of specific cell types is mandatory before anti-tumor therapy such as chemotherapy or radiotherapy to ensure effective response as well as conformance with the policy of the country's national health insurance system. Recently, the European Society of Gastrointestinal Endoscopy (ESGE) guidelines $^{12}$ on EUS-guided tissue acquisition attempted to establish some recommendations by reporting the suggested and accepted indications for this procedure. Generally, EUS-guided tissue acquisition provides high diagnostic accuracy (sensitivity and specificity, $85 \%$ to $89 \%$ and $96 \%$ to $99 \%$, respectively, according to three metaanalyses ${ }^{13-15}$ ) with a relatively low negative predictive value for the diagnosis of pancreatic malignancy, and is also associated with a very low incidence of adverse events, even in long-term adverse events such as tumor seeding. ${ }^{16}$ Before this, tissue confirmation had not generally been recommended prior to curative resection for potentially resectable pancreatic tumors inoperable patients. Although the predominant cell type is adenocarcinoma, the differential diagnosis of a solid pancreatic tumor can include other 
definite malignant tumors such as lymphoma, squamous cell carcinoma, and neuroendocrine tumors, potentially the premalignant tumors such as a gastrointestinal stromal tumor, solid pseudopapillary tumor, other metastatic malignancies from kidney, colon, lung or other organs, and even benign lesions such as autoimmune pancreatitis and focal mass-forming chronic pancreatitis. Fig. 1 shows several EUS findings from solid pancreatic tumors other than the typical pancreatic ductal adenocarcinoma. In addition, pancreatic tumor with cystic components such as intrapapillary mucinous neoplasm, mucinous cystadenoma, serous cystadenoma, and even simple cyst or pseudocyst has been estimated to account for approximately $6 \%$ of patients undergoing pancreatic resection. ${ }^{17}$ Therefore, to minimize unnecessary surgeries, a pretreatment tissue confirmation is mandatory and recommended in most cases: (1) unresectable pancreatic tumor; (2) resectable/borderline resectable pancreatic tumor; (3) autoimmune pancreatitis or mass-forming chronic pancreatitis; or (4) neuroendocrine pancreatic tumors and other pancreatic tumors.

\section{Which needle is recommended with regard to diagnostic yield, adverse events, and ease to use depending on the location of the lesion?}

1) Should biopsy needles (FNB needles) rather than standard needles (FNA needles) be used?

\section{Recommendation}

For routine EUS-guided tissue acquisition of pancreatic solid tumors, FNA and FNB needles are equally recommended. When the primary aim of sampling is to obtain a histologic core tissue specimen (e.g., focal autoimmune pancreatitis or neuroendocrine tumors), KSGE recommends using FNB needles (level of evidence: moderate, grade of recommendation: strong).

\section{2) Should 19-gauge vs 22 -gauge vs 25 -gauge needles be used?}

\section{Recommendation}

Our group suggests that no specific type or diameter of the needle has higher diagnostic accuracy than others in EUS-guided tissue acquisition for solid pancreatic tumors. However, 22-gauge needles tend to have superior outcomes compared to 19-gauge or 25-gauge needles in terms of optimal histologic core procurement and sample adequacy (level of evidence: low, grade of recommendation: weak).

There are various types and diameters of needle used in EUS-guided tissue acquisition for solid pancreatic tumors in the market. Furthermore, a new type of needle specially designed to procure histologic core preserving intact histologic architecture for suitable pathological evaluation has been introduced recently. These devices, collectively called FNB needles, has the unique feature of a needle tip which has either a side-slot (core trap) or a special geometry of the cutting tip (Table 3$).^{18}$

EUS-guided tissue acquisition for cytopathologic evaluation through FNA or FNB using specially designed core
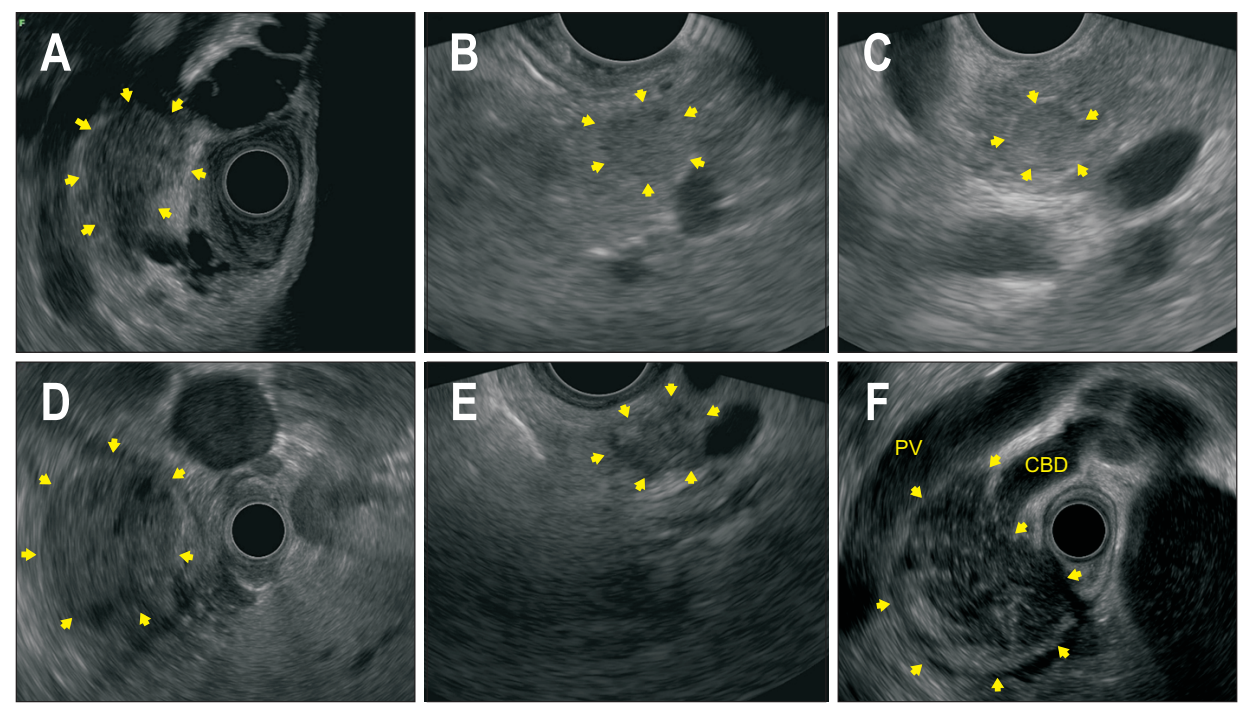

Fig. 1. Endoscopic ultrasound image of different solid pancreatic tumors (arrows). (A) Solid lesion located in the pancreatic head, corresponding to pancreatic ductal adenocarcinoma. (B) Pancreatic neuroendocrine tumor located in the pancreatic tail. (C) Insulinoma located in the pancreatic tail. (D) Solid pseudopapillary tumor located in the pancreatic tail. (E) Mass-forming chronic pancreatitis located in the pancreatic neck. (F) Massforming autoimmune pancreatitis located in the pancreatic head with bile duct obstruction.

$\mathrm{PV}$, portal vein; $\mathrm{CBD}$, common bile duct. 
Table 3. Needles Available on the Market in Korea for Use in EUS-Guided Tissue Acquisition from Solid Pancreatic Tumors ${ }^{18}$

\begin{tabular}{lllc}
\hline Manufacturer & \multicolumn{1}{c}{ Model } & Needle type & Needle diameter lgauge) \\
\hline \multirow{2}{*}{ Boston Scientific } & Expect $^{\text {TM }}$ Slimline (SL) & Aspiration needle & $19,22,25$ \\
& Acquire ${ }^{\text {TM }}$ Flex & Biopsy needle & 22,25 \\
Cook & EchoTip Ultra & Aspiration needle & $19,22,25$ \\
& EchoTip ProCore & Biopsy needle & $19,22,25$ \\
Olympus & EchoTip ProCore & Biopsy needle & $20^{*}$ \\
& EZ-shot 3 & Aspiration needle & $19,22,25$ \\
Medi-Globe & EZ-shot 3 with sideport & Aspiration needle & $19,22,25$ \\
Finemedix & SonoTip Pro Control & Aspiration needle & $19,22,25$ \\
& ClearTip & Aspiration needle & $19,22,25$ \\
& ClearTip & Biopsy needle & $19,22,25^{\dagger}$ \\
\hline
\end{tabular}

EUS, endoscopic ultrasound.

*A newly marketed needle has been designed with a core trap and bevel system to increase diagnostic yield and enhance the procurement of the histologic core, while other gauge needles $\left(19,22\right.$, and 25 gauge) have a reversed bevel system; ${ }^{\dagger} A$ newly marketed needle has been designed with a core trap and bibevel system to increase diagnostic yield and enhance the procurement of the histologic core.

needles has become a key technique in the diagnosis of solid pancreatic tumors. ${ }^{19}$ Standard needles without these reinforcement geometries are here classified as FNA needles. Needles with a side port (EZ-Shot 3 with side port, Olympus) were classified as FNA needles because the side port of this needle system does not have a bevel design for cutting the tissue. ${ }^{18}$ A recent network meta-analysis ${ }^{19}$ consisting of 15 parallel trials and 12 cross-over studies demonstrated that traditional pairwise meta-analyses failed to report superiority in the diagnostic accuracy of any needle over another in a head-to-head comparison. In detail, there was no difference regarding the diagnostic accuracy between the 22-gauge FNB and FNA approach (relative risk [RR], 1.02; 95\% confidence interval [CI], 0.97 to 1.08 ) or between the 25-gauge and 22-gauge FNA needle (RR, 1.03 ; $95 \%$ CI, 0.98 to 1.07 ). Furthermore, no differences were noted between the 22-gauge FNA and 19-gauge FNA needles (RR, 1.07 ; 95\% CI, 0.78 to 1.46). In this metaanalysis, no significant difference was reported between the two types of 22-gauge FNB needles (Fork-tip vs Franseen: RR, $0.96 ; 95 \%$ CI, 0.87 to 1.06 ). Similar to the results of direct meta-analyses, there was no significant difference in diagnostic accuracy between FNB and FNA needles, or 22-gauge and 25-gauge needles.

In regard to sample adequacy, 22-gauge FNB had significantly better sample adequacy than 25-gauge FNA (RR, $0.79 ; 95 \% \mathrm{CI}, 0.68$ to 0.92 ) in the direct meta-analysis, whereas 22-gauge FNA was more likely to obtain an adequate sample compared with 19-gauge FNA needles (RR, 1.13 ; $95 \%$ CI, 1.00 to 1.28$)$. However, the results of network meta-analyses did not indicate that any of the tested needles were superior to another in terms of obtaining an adequate sample.

In regard to histologic core procurement rate, 25-gauge FNB had a significantly superior outcome than 25-gauge
FNA (RR, 1.17; 95\% CI, 1.00 to 1.36 ) according to a direct meta-analysis. ${ }^{20}$ Furthermore, 22-gauge FNB was found to be superior to 25 -gauge FNA (RR, 4.56; 95\% CI, 2.49 to 8.35). In other direct comparisons, the histologic core procurement rate was comparable for different needles including the 22-gauge FNB and 22-gauge FNA needle (RR, 1.01; $95 \%$ CI, 0.89 to 1.15 ).

\section{What is the optimal number of needle passes when rapid on-site cytologic evaluation (ROSE) is not available?}

\section{Recommendation}

Because ROSE is not available in Korea, our group suggests that 4 needle passes using EUS-guided tissue acquisition may be adequate to achieve appropriate diagnosis in patients with pancreatic tumors. Pancreatic tumors less than $2 \mathrm{~cm}$ may require a higher number of needle passes. Furthermore, fewer needle passes might be required for the EUS-FNB procedure (level of evidence: low, grade of recommendation: weak).

The optimal number of needle passes for accurate diagnosis of solid pancreatic tumors has been the subject of debate. The execution of more needle passes than necessary may cause potential procedure-related adverse events and also a longer procedure time. ${ }^{21}$ In contrary to this, carrying out a suboptimal number of needle passes may increase the rate of false-negative results and lead to unnecessary expenses due to repeat interventions.

Per-pass analyses from recent prospective trials ${ }^{21-25}$ have demonstrated that 3 to 4 passes with a standard FNA needle or 2 to 3 passes with an FNB needle with a reversed bevel system are required to establish optimal sampling for pancreatic solid tumors; this produces a sensitivity for 
malignancy of more than $90 \%$. According to one recent study, the cumulative sensitivity is significantly inferior for tumors $\leq 2 \mathrm{~cm}$ than for tumors $>2 \mathrm{~cm}$, based on 4 passes with a standard FNA needle. More than 4 needle passes significantly improved the diagnostic sensitivity, even for smaller tumor sizes. ${ }^{21}$ Recently, needle designs have markedly evolved to optimize the acquisition of histologic core in EUS-guided tissue acquisition (i.e., ProCore, Acquire and SharkCore needle). Several prospective comparative studies $^{21-25}$ between FNB and conventional FNA needles have revealed that fewer needle passes are required for diagnostic confirmation when using an FNB needle.

\section{How we do in cases with inadequate or inconclusive pathological results? Repeat EUS- guided tissue acquisition?}

\section{Recommendation}

Repeat EUS-guided acquisition provides a conclusive diagnosis in the majority of cases with indeterminate cytopathological diagnoses and, therefore, should be strongly recommended ahead of other modalities, such as biopsy under computed tomography-guidance or diagnostic surgical exploration (level of evidence: moderate, grade of recommendation: strong). Furthermore, the K-ras mutation can be an available option to increase the diagnostic accuracy for inconclusive samples (level of evidence: low, grade of recommendation: weak).

The Papanicolaou Society of Cytopathology developed a set of guidelines for standardized terminology and nomenclature of pancreatobiliary cytology specimens in 2014 (Table 4). ${ }^{26}$ It emanates from expert opinions, a systematic review of the literature, international discussions among pathologists at several meetings during an 18 month, and synthesized conclusion from online conferences on the draft document on the Papanicolaou Society of Cytopathology web site (www.papsociety.org). Repeat EUS-guided tissue acquisition appears to be a reasonable option for an inconclusive pathologic result for suspected pancreatic malignancy. ${ }^{27,28}$ Eloubeidi et al. ${ }^{29}$ suggested the usefulness of repeat EUS-guided tissue acquisition for inconclusive index pathologic results. Among 24 (4.6\%) patients who underwent repeat EUS-guided tissue acquisition, a true final diagnosis could be determined in 20 patients, with an accuracy of $84 \%$. In another multicenter retrospective cohort study, 292 cases with adequate follow-up among a total of 4,522 EUS-FNA procedures were assigned to "atypical" or "suspicion of malignancy" categories. The proportion of malignancy in "atypical" and "suspicion of malignancy" categories were $79.2 \%$ and $96.3 \%$, respectively. If the "suspicion of malignancy" category was defined as malignancy and the "atypical" category was defined as a benign disease, the positive predictive value was $96.3 \%$ (95\% CI, 92.6 to 98.5), and the negative predictive value was $20.8 \%$ (95\% CI, 13.4 to 30.0). Thus, the authors demonstrated that defining "suspicion of malignancy" categorized tumors as malignant optimizes the diagnostic sensitivity and specificity.

Furthermore, K-ras mutation analysis can be another useful option for differentiation of pancreatic mass lesions and may complement other diagnostic tools, especially when the results of EUS-FNA are inconclusive. In one meta-analysis, ${ }^{31}$ the author reported that the estimated sensitivity and specificity of K-ras gene analysis alone were $76.8 \%$ and $93.3 \%$, respectively, and those of combined EUS-FNA plus K-ras mutation analysis were $88.7 \%$ and $92 \%$, respectively. Overall, applying K-ras mutation analysis to patients with inconclusive EUS-FNA results may reduce the false-negative rate to approximately $50 \%$, the false-positive rate to approximately $10 \%$, and the repeatbiopsy rate from $12.5 \%$ to $6.8 \%$. Although K-ras mutation analysis can be useful for cases with inconclusive results and spare unnecessary repetition of EUS-guided tissue acquisition, it is not always commercially available in many centers and should be cautiously interpreted within the clinical context. ${ }^{31}$

\section{Sample obtaining techniques}

1) Should ROSE always be used?

\section{Recommendation}

Our group suggests that routine application of ROSE cannot guarantee an improvement in diagnostic accuracy and performance in terms of sensitivity and specificity. Nevertheless, application of ROSE is expected to achieve higher per-case accuracy than non-application (level of evidence: low, grade of recommendation: weak).

The diagnostic accuracy of EUS-guided tissue acquisition under ROSE is reported to be higher than $90 \%$ in most studies; $;^{32-35}$ however, comparable results have also been reported from some trials without ROSE. In one recent meta-analysis, ${ }^{36}$ authors found that there was no indication that the application of ROSE improved the diagnostic yield (risk difference [RD], 0.04; 95\% CI, 0.05 to $0.13)$. Therefore, routine application of ROSE could not guarantee superior outcomes in clinical practice at tertiary care centers. In samples where the diagnosis was properly performed, and malignancy was defined as samples categorized as "highly suggestive" and "definitive malignancy," 
Table 4. Standardized Terminology and Nomenclature for Pancreatobiliary Cytology Specimens in $2014^{26}$

\begin{tabular}{|c|c|c|}
\hline Category & Nomenclature & Definition \\
\hline Category I & Non-diagnostic & $\begin{array}{l}\text { A non-diagnostic cytology specimen is one that provides no diagnostic or useful information about the solid } \\
\text { or cystic lesion sampled; for example, an acellular aspirate of a cyst without evidence of a mucinous etiol- } \\
\text { ogy such as thick colloid-like mucus, elevated CEA or KRAS/GNAS mutation (see Category IV). Any cellular } \\
\text { atypia precludes a non-diagnostic report. }\end{array}$ \\
\hline Category II & $\begin{array}{l}\text { Negative } \\
\quad \text { (for malignancy) }\end{array}$ & $\begin{array}{l}\text { A negative cytology sample is one that contains adequate cellular and/or extracellular tissue to evaluate or } \\
\text { define a lesion that is identified on imaging. When using the negative category, one should give a specific } \\
\text { diagnosis when practical, including: } \\
\text { Benign pancreatobiliary tissue in the setting of vague fullness and no discrete mass } \\
\text { Acute pancreatitis } \\
\text { Chronic pancreatitis } \\
\text { Autoimmune pancreatitis } \\
\text { Pseudocyst } \\
\text { Lymphoepithelial cyst } \\
\text { Splenule/accessory spleen }\end{array}$ \\
\hline Category III & Atypical & $\begin{array}{l}\text { The category of atypical should only be applied when there are cells present with cytoplasmic, nuclear, or } \\
\text { architectural features that are not consistent with normal or reactive cellular changes of the pancreas or } \\
\text { bile ducts and are insufficient to classify them as a neoplasm or suspicious for a high-grade malignancy. } \\
\text { The findings are insufficient to establish an abnormality explaining the lesion seen on imaging. Follow-up } \\
\text { evaluation is warranted. }\end{array}$ \\
\hline \multirow[t]{2}{*}{ Category IV } & Neoplastic: benign & $\begin{array}{l}\text { This interpretation category connotes the presence of a cytological specimen that is sufficiently cellular and } \\
\text { representative, with or without the context of clinical, imaging, and ancillary studies, to be diagnostic of a } \\
\text { benign neoplasm. }\end{array}$ \\
\hline & Neoplastic: other & $\begin{array}{l}\text { This interpretation category defines a neoplasm that is either premalignant such as intraductal papillary } \\
\text { neoplasm of the bile ducts, intraductal papillary mucosal neoplasms, or mucinous cystic neoplasm with } \\
\text { low, intermediate, or high-grade dysplasia by cytological criteria, or a low-grade malignant neoplasm } \\
\text { such as well-differentiated primitive neuroectodermal tumor or solid-pseudopapillary neoplasm. While } \\
\text { mucinous epithelium in biliary brushing specimens may indeed represent a neoplastic change, given the } \\
\text { lack of evidence-based literature on the cytological interpretation, histology and management of these le- } \\
\text { sions, low-grade mucinous change of biliary epithelium will remain in the "atypical" rather than "neoplas- } \\
\text { tic" category. }\end{array}$ \\
\hline Category V & $\begin{array}{l}\text { Suspicious } \\
\text { (for malignancy) }\end{array}$ & $\begin{array}{l}\text { A specimen is suspicious for malignancy when some, but an insufficient number of the typical features of } \\
\text { a specific malignant neoplasm are present; mainly pancreatic adenocarcinoma. The cytological features } \\
\text { raise a strong suspicion for malignancy, but the findings are qualitatively and/or quantitatively insufficient } \\
\text { for a conclusive diagnosis, or tissue is not present for ancillary studies to define a specific neoplasm. The } \\
\text { morphologic features must be sufficiently atypical that malignancy is considered more probable than not. }\end{array}$ \\
\hline Category VI & $\begin{array}{l}\text { Positive for } \\
\text { malignancy }\end{array}$ & $\begin{array}{l}\text { A group of neoplasms that unequivocally display malignant cytologic characteristics and include pancreatic } \\
\text { ductal adenocarcinoma and its variants; cholangiocarcinoma, acinar cell carcinoma, high-grade neuroen- } \\
\text { docrine carcinoma (small cell and large cell), pancreatoblastoma, lymphomas, sarcomas and metastases } \\
\text { to the pancreas. }\end{array}$ \\
\hline
\end{tabular}

CEA, carcinoembryonic antigen; KRAS, Kirsten rat sarcoma viral oncogene homolog; GNAS, guanine nucleotide-binding protein/ $\alpha$-subunit.

there was no significant difference in the rate of malignant diagnoses when ROSE was and was not applied (RD, 0.08; $95 \%$ CI, 0.09 to 0.25 ). Therefore, the results have shown that the application of ROSE does not provide superior outcomes in terms of the impact of ROSE on diagnostic performance. Furthermore, it has been reported that applying ROSE does not also have a beneficial effect on cellular yield. Thus, the above finding seems to be reasonable since a similar cellular yield should result in comparable diagnostic efficacy. ${ }^{36}$

However, for a given sample adequacy rate and the number of needle passages, ROSE is expected to have higher per-case accuracy than sampling without ROSE. ${ }^{37}$ In other words, trials with ROSE have demonstrated a higher per-case diagnostic accuracy than trials without ROSE. This suggests that the relationship between per-case diagnostic accuracy and needle passes depends on the use of ROSE.

\section{2) Should the needle stylet be used?}

\section{Recommendation}

The use of a stylet during EUS-guided tissue acquisition does not appear to guarantee any advantages with regards to the adequacy of the specimen, diagnostic yield, nor regarding prevention of needle clogging by gut wall tissue (level of evidence: moderate, grade of recommendation: weak). 
Regarding sample adequacy, the pooled data from a recent meta-analysis ${ }^{38}$ demonstrated that there were no significant differences between groups in which the stylet was or was not used, although one study ${ }^{39}$ showed superior adequacy of the sample without the stylet. Furthermore, there were no differences in the cellularity between groups in which the stylet was or was not used despite the theoretical advantage of the stylet preventing blockage or contamination of the needle by the intestinal mucosa. ${ }^{38}$ In one prospective RCT of 550 lesions in which the performance of EUS-FNA with or without a stylet was compared, Wani et $a .^{40}$ concluded that there was no significant difference between groups in which the stylet was or was not used in terms of sample cellularity. This lack of a significant difference among several studies may be attributed to heterogeneity in the cytopathologists' definitions of sample adequacy and cellularity, although predefined criteria were used to compare the cytopathologic characteristics of the specimens and the cytopathologists were blinded to the specimen procurement technique. Furthermore, there may have been intra- and inter-observer agreement variability among cytopathologists in the assessment of EUSFNA specimens. Additionally, the use of a stylet did not change the contamination rate nor the frequency of bloody and/or inadequate samples despite the theory that using a stylet will prevent tissue from blocking the needle tip and/ or contamination of the sample before entering the FNA target lesion. ${ }^{39}$

3) Should the no-suction, slow-pull-back, standard (5-10 $\mathrm{mL}$ ) suction, high negative pressure, or wet suction method be used?

\section{Recommendation}

Our group suggests that routine application of suction is recommended in cases where cellularity is poor, such as fibrotic lesions in chronic pancreatitis, whereas it is discouraged in non-fibrotic lesions which may contain necrosis and blood to minimize contamination of the cellular sample (level of evidence: moderate, grade of recommendation: weak). Also, the slow-pull-back technique may be more effective in terms of adequate tissue acquisition and require fewer needle passes for solid pancreatic tumors (level of evidence: low, grade of recommendation: weak).

Theoretically, the application of suction on the needle mount was a standard practice based on the understanding that negative pressure would increase cellularity. One $\mathrm{RCT}^{41}$ comparing EUS-FNA with and without suction, demonstrated that suction resulted in superior diagnostic outcomes in terms of higher sensitivity and lower blood contamination rates, although the proportion of pancreatic tumors in this study was less than $20 \%$ among the various included lesions. Another recent RCT, ${ }^{42}$ comparing only pancreatic solid tumor samples acquired with and without suction, found that the application of suction resulted in higher cellularity and sensitivity but also a higher blood contamination rate. Although the effectiveness of suction has been demonstrated in several trials, it can decrease the sample quality due to the increased blood contamination. Puri et al. ${ }^{41}$ found that the suction technique to be also associated with an increased number of microscopic slides (17.8 \pm 7.1 vs $10.2 \pm 5.5 ; \mathrm{p}=0.001)$ and higher bloodcontamination rate when using a 22 -gauge needle. Another study, ${ }^{42}$ assessing the results of 324 samples from 81 patients, identified a significantly higher diagnostic yield ( $85.2 \%$ vs $75.9 \%$; $\mathrm{p}=0.004)$, sensitivity $(82.4 \%$ vs $72.1 \%$; $\mathrm{p}=0.005)$, cellularity $(\mathrm{p}<0.001)$, and blood-contamination $(\mathrm{p}<0.001)$ in the suction group, with no significant differences in terms of specificity ( $96.8 \%$ vs $100 \%)$.

As an alternative to suction, the slow-pull-back technique was recently introduced for EUS-FNA or FNB of solid pancreatic lesions. ${ }^{23,43,44}$ In contrast to standard suction techniques, this technique minimizes negative pressure by removing the stylet from the needle slowly and continuously. ${ }^{45}$ In a recent $\mathrm{RCT}^{46}$ comparing the slowpull-back technique, standard negative-suction technique after stylet removal, and non-suction technique after stylet removal for EUS-FNB, the negative-suction technique had a higher blood contamination rate and did not increase the rate of core-tissue acquisition. The authors demonstrated that the slow-pull-back technique provided greater cellularity with less blood contamination compared with the other techniques, although there was no significant difference in the core-tissue diagnostic adequacy for malignancy between the groups. Furthermore, the slow-pull-back technique was associated with increased diagnostic accuracy. In another prospective study, ${ }^{47}$ the slow-pull-back technique, compared to the standard suction technique, provided faster and more cost-effective results due to lower blood contamination and decreased the number of slides while guaranteeing comparable results in terms of diagnostic yield, cellularity, and sufficient histological samples.

\section{4) Should the fanning technique be used rather than the standard technique?}

\section{Recommendation}

Our group suggests that the fanning technique for EUS-guided tissue acquisition offers technically acceptable feasibility and superior diagnostic outcomes, 
including fewer needle passes required to establish the definite diagnosis, than the standard technique (level of evidence: moderate, grade of recommendation: strong). Furthermore, the torque technique, similar to the fanning technique, also showed better outcomes regarding optimal histologic core procurement and diagnostic accuracy in comparison with the standard technique (level of evidence: low, grade of recommendation: weak).

Since its introduction in $2013,{ }^{24}$ the fanning technique has emerged as a standard technique for EUS-guided tissue acquisition of pancreatic solid tumors. This technique is based on the targeting of multiple areas within the mass during to-and-fro movements of the needle using the up/ down knob of the endoscope on each needle pass. Bang et al. reported that the fanning technique required fewer passes than the standard technique for an accurate diagnosis; however, this trial failed to show a difference in diagnostic accuracy between the fanning and standard techniques (96.4\% and $76.9 \%)$. Theoretically, the application of the fanning technique can increase the likelihood of achieving a true diagnosis under ROSE on the first pass, thereby reducing the risk of inconclusive results. Moreover, the fanning technique has no additional risk or financial costs. However, the evidence is limited to only one study by Bang et al. ${ }^{24}$ that revealed some advantages with respect to the number of needle passes and achievement of a true diagnosis but failed to verify a significant impact of the technique on diagnostic outcomes.

Seeking another maneuver with equal or superior diagnostic outcomes as the fanning technique without its limitations, Park et al. ${ }^{48}$ invented an alternative and similar technique called the "torque technique." Torque is applied by twisting the body of the echoendoscope to the right (clockwise) or left (counter-clockwise) without using the left/right control knob. In that study, the authors demonstrated that the torque technique was significantly superior to the standard technique with respect to sensitivity and diagnostic accuracy. In addition, this technique had a superior procurement rate of histologic core tissue and more optimal histologic cores compared to the standard technique.

\section{Methods of specimen processing}

\section{Recommendation}

Diagnostic performances are most affected by preparation processing (direct smear, liquid-based cytology [LBC], cell block, and histology) and by staining techniques (Papanicolaou methods, Diff-Quik, hematoxylin and eosin, and Giemsa). Furthermore, specialized im- munohistochemistry (IHC) staining aids in the diagnosis of epithelial components with cytologic atypia and in differentiating various tumor cell types. The use of IHC staining and molecular/genetic assays can enhance the value of oncological predictions and lead to tailor-made treatments (level of evidence: low, grade of recommendation: weak).

1) Which technique should be used when preparing/ processing samples? Smear cytology, LBC, cell block, or histologic preparations?

Diagnostic performance differs by cytologic or histologic sample preparations (smear, rapid cytology, LBC, cell block, and histology) and by staining methods. ${ }^{49}$ Ideally, samples from solid pancreatic tumors should be examined by both histological and cytological evaluation.

\section{(1) Smearing and rapid cytology of EUS-FNA samples}

Direct smear facilitates rapid staining and cytological diagnosis; thus, is an essential step in processing EUS-FNA specimens from pancreatic tumors. The assistant nurse places the stylet into the needle channel to extrude the aspirated sample onto the slide. Appropriate quantities of acquired sample material should be mounted on the slide for inspection of optical properties of the optimal specimen. Applying large quantities of the sample at once can lead to thick smears (with cells obscured within clusters) or clotting artifacts, while watery or small quantities of sample do not smear well on the slide causing air-drying artifacts. ${ }^{50}$ Insufficient sample quantities, which cannot pick up the whitish component, can be processed by the cytospin method. In this method, the sample should first be immersed in saline and then centrifuged at 2,000-3,000 rpm for 2 to 3 minutes before being applied to the slide. ${ }^{51}$ This technique involves separating the sample into multiple small aliquots as well as treatment with a hemolytic agent and mucus softener. This is favorable as it allows for optimal sample preparation with adequate cellularity and minimal artifacts.

When smear specimens are made using two slide glasses, usually one slide is prepared using the conventional airdried method for rapid cytology with Diff-Quik, whereas the other slide is fixed in ethanol for later staining using Papanicolaou and hematoxylin and eosin stain. ${ }^{52}$ DiffQuik, a rapid version of Giemsa and Papanicolaou staining, allows for rapid cytological analysis in under a minute, even with watery samples containing an abundance of exfoliated cells. ${ }^{50}$

(2) Liquid-based cytology

Almost all false-negative cytologic results are due to 
errors in sampling, preparation of the sample, and interpretation of the sample. For this reason, LBC is an effective technique for sample preparation which can be manipulated automatically within only 2 to 4 minutes per sample after the acquisition of cytologic materials. ${ }^{53}$ The results of comparisons between the diagnostic performance of LBC and smears for pancreatic cancer are conflicting. While Siddiqui et al..$^{54}$ found LBC to be superior (LBC vs smear; $91 \%$ vs $58 \%$ ), Qin et $a l^{55}$ found the techniques to be similar (LBC vs smear; $73.3 \%$ vs $70 \%$ ), and others found $\mathrm{LBC}$ to be inferior ${ }^{56-58}$ (LBC vs smear; $61.7 \%-75.0 \%$ vs $91.6 \%-$ $97.9 \%)$. However, there was a consensus that LBC specimens showed clearer backgrounds. LBC has the advantage of reducing false-negative results because it provides better specimen preservation, a clearer background with less mucin, necrotic material, and inflammatory cells, and higher cellularity, by reducing artifacts and extracellular elements compared with conventional smear cytology. Furthermore, prepared samples from LBC can be used for genetic analysis and IHC to provide further cytologic information.

\section{(3) Cell block}

The cell block is an effective technique that overcomes the disadvantages of conventional smear cytology and can lead to a definite diagnosis through IHC and molecular assays. Various cell block techniques have been developed over time: the traditional manual, involving rinsing the sample with $50 \%$ ethanol; the sodium alginate method, involving fixing the sample in $10 \%$ formalin and $1 \%$ sodium alginate; and the novel Cellient Automated Cell Block System (Hologic Inc). All methods involve embedding the collected cell pellets in paraffin and cutting thin 3 to $5 \mu \mathrm{m}$ sections before staining. ${ }^{59}$ Sample prepared by cell block can be applied to IHC and specific molecular assays to differentiate between malignant and benign lesions and to determine tumor phenotypes. In one study ${ }^{60}$ comparing the diagnostic abilities of the cell block and smear cytology using 33 pancreatic tumors or lymph node samples acquired through EUS-FNA, the cell block technique with IHC was superior to smear cytology in regard to sensitivity ( $92 \%$ vs $60 \% ; \mathrm{p}=0.02$ ) and accuracy ( $94 \%$ vs $61 \% ; \mathrm{p}=0.003$ ).

\section{(4) Histology of EUS-FNA/B samples}

Recent technical and instrumental improvements in EUS-FNB for pancreatic solid tumors have enabled adequate histologic sampling, even using 22 -gauge or 25 -gauge needles. According to a recent network metaanalysis, ${ }^{19}$ two RCTs reported that 25 -gauge FNB was superior to 25 -gauge FNA (RR, 1.17; $95 \% \mathrm{CI}, 1.00$ to 1.36$)^{20}$ and that 22-gauge FNB was more predominant than 25-gauge FNA (RR, 4.56; 95\% CI, 2.49 to 8.35$)^{61}$ in regards to opti- mal histologic core procurement. They also reported that the 22-gauge FNB and 22-gauge FNA needles (RR, 1.01; 95\% CI, 0.89 to 1.15 ) did not differ in terms of optimal histologic core procurement. IHC and molecular assays can be applied more easily to FNB samples than to samples from cytology or cell block. Ideally, EUS-guided tissue acquisition of pancreatic tumors should routinely include a histological evaluation by biopsy in addition to cytology.

\section{2) Special handling (IHC, telecytology, ancillary} molecular analysis, and chemosensitivity): how to do it and in which cases?

IHC staining focuses on the diagnosis of epithelial components with histological atypia and differential diagnosis of various tumors such as mass-forming chronic pancreatitis, pancreatic neuroendocrine tumor (PNET), and autoimmune pancreatitis through preserving histologic architecture. Genetic analysis can aid in tailored treatment in individuals with pancreatic cancer and prediction of prognosis. Telecytology, which is a remote cytopathology diagnostic system based on online transmitted microscope images, enables real-time diagnosis of the samples by expert cytopathologists.

\section{(1) IHC and special staining}

IHC can be applied to histologic cores from EUS-FNB, cell block, and even LBC. It can differentiate benign and malignant lesions and reduces false negatives by staining for tumor suppressor gene proteins (e.g., TP53 or E-cadherin $)^{62}$ and tumor-associated proteins (e.g., mesothelin, S100P or fascin). ${ }^{63}$ Furthermore, IHC can determine tumor aggressiveness or predict the clinical behavior of PNET using the Ki-67 index on large prepared pieces of tumor tissue from EUS-FNB (>2,000 cells). ${ }^{64}$ In addition, IHC can also identify the phenotype of the tumor and eventually the cell origin (Table 5). ${ }^{49}$

\section{(2) Telecytology or telepathology}

The most ideal system for the rapid cytological diagnosis of samples from EUS-FNA is ROSE. As mentioned earlier, however, the usefulness of the ROSE system is limited both in terms of time required and availability of technology, even in an experienced tertiary hospital. As a substitute for ROSE, telecytology was introduced in 1997 by the International Academy of Cytology Task Force summary to save time and labor of cytopathologists and to enable real-time analysis of samples from EUS-FNA performed at remote locations, even at field hospitals. ${ }^{65}$ It is a remote cytopathology diagnostic system based on online transmitted microscope images. It consists of bidirectional communication using an internet connection; physicians 
Table 5. Specific Indicators in Immunohistochemistry Staining ${ }^{47}$

\begin{tabular}{ll}
\hline Marker for immunohistochemistry & \\
\hline $\begin{array}{l}\text { Cytokeratin (CK) } \\
\text { Mucin core protein (MUC) }\end{array}$ & Epithelial cell tumors \\
CK 7 and 20 & Gastrointestinal tract adenocarcinoma (especially biliary tract cancer) \\
HepPar-1 & Hepatocellular carcinoma \\
Glypican 3 & \\
AFP & Solid pseudopapillary tumors \\
CD10 & \\
B-Catenin & Neuroendocrine tumors \\
Chromogranin A & \\
Synaptophysin & Acinar cell carcinoma \\
Trypsin & Intraductal tubular or tubulo-papillary neoplasms \\
Lipase & \\
BCL10 & \\
MUC6 & B cell marker \\
L26 & T cell marker \\
UCHL1 & Malignant lymphoma \\
LCA & Autoimmune pancreatitis \\
IgG4 subtype & Peripancreatic tuberculous lymphadenopathy \\
Ziehl-Neelsen &
\end{tabular}

process samples from each pass of a EUS-FNA using DiffQuik smear and selects several representative cytological images. Thereafter, the images are transmitted to the pathologist's computer through a network system. Cytopathologists then report the results of the images by phone. Recent trials have demonstrated that each image can be transmitted within 0.5 to 3 seconds with high resolution. ${ }^{66}$ When combining the pre-screen time, scan time, and diagnosis time, telecytology takes an average of approximately 12 minutes per sample. ${ }^{66}$ This is considerably shorter than the time required for traditional methods including the time of transportation to the department of pathology and the interval between aspirations, which can take an average of over 30 minutes. ${ }^{67}$ When comparing telecytopathology with regular ROSE regarding diagnostic accuracy, one retrospective study ${ }^{66}$ reported that the Kappa values of telecytopathology were less than those of ROSE for reaching the final diagnosis although the difference was not statistically significant. Thus, the author concluded that the application of telecytopathology could be a valid substitute for ROSE in EUS-guided tissue acquisition of solid pancreatic tumors. The slight inferiority of telecytology compared with ROSE was considered to reflect the fact that accurate assessment using telecytology largely depends on the initial screener who sends the images for review. ${ }^{68,69}$ The principle drawback of a static telecytology method is the subjectivity of image sampling, since a snapshot image may not truly be representative of the whole slide. Therefore, experienced physicians are recommended for sample preparation and image selection.
(3) Molecular analysis

Many molecular analyses for the detection of epigenetic and genetic alterations have been conducted using samples from EUS-guided tissue acquisition for a pancreatic tumor. ${ }^{70-72}$ In addition, fluorescence in situ hybridization or digital image analysis are also performed for detecting chromosomal abnormalities in chromosomes 3, 7, 17, or 9 p21, with $11 \%$ to $27 \%$ sensitivity. ${ }^{73,74}$ Among these, K-ras gene mutations are reported in more than $75 \%$ of pancreatic cancer cases, ${ }^{75}$ and it appears to be present in the early stages of the carcinogenesis process. ${ }^{76}$ Thus, Kras gene mutation analysis has been considered a possible biomarker for early detection of pancreatic cancer. In a recent meta-analysis of the diagnostic accuracy of K-ras mutation analysis for pancreatic cancer, the pooled sensitivity and specificity of EUS-FNA with the traditional cytopathologic examination were $80.6 \%$ and $97 \%$, respectively. However, K-ras mutation analysis could be helpful for inconclusive results from index EUS-FNA by reducing the false-negative rate to $55.6 \%$ and the false-positive rate to $10.7 \%$. Moreover, the repeat sampling rate was reduced from $12.5 \%$ to $6.8 \%{ }^{31}$ Therefore, the examination of the Kras mutation can be generally applied to inconclusive cases after index EUS-guided tissue acquisition. However, when $\mathrm{K}$-ras mutation analysis is applied as an additional tool in the differential diagnosis of solid pancreatic tumors, clinicians must recognize that the significant reduction in the false-negative rate is counterbalanced by a relatively small increase in the false-positive rate. Thus, $\mathrm{K}$-ras mutation analysis should always be cautiously interpreted within a clinical context. 
(4) Chemosensitivity and prediction of prognosis

Many molecular abnormalities based on DNA, RNA, or proteins in pancreatic tumor tissues have been evaluated and determined to be indicators for prognosis ${ }^{77}$ and sensitivity to chemoagents. ${ }^{78,79}$ Among these, a point mutation of the K-ras oncogene, which is found in more than $90 \%$ of pancreatic cancers, is reported as a negative prognostic factor. $^{71,78}$ Overexpression of epidermal growth factor receptor in mRNA is also confirmed as a strong prognostic marker ${ }^{78}$ which is easily detected in EUS-FNA samples. ${ }^{80}$ As well as prognostic factors, histologic samples using EUS-guided tissue acquisition for pancreatic cancer can predict the response to gemcitabine-based chemotherapy. ${ }^{81,82}$ According to a recent study by a French group, a transcriptome analysis from 17 xenografts of pancreatic cancer cells obtained by EUS-guided tissue acquisition could predict sensitivity to several anticancer drugs commonly used to treat pancreatic cancer. ${ }^{83}$ In addition, Wakatsuki et al. ${ }^{84}$ used the adenosine triphosphate assay kit to determine the chemosensitivity of pancreatic cancer to chemotherapeutic agents. Following an indication of sensitivity to paclitaxel, they proceeded with this treatment, resulting in complete response and disappearance of pancreatic cancer.

\section{Adverse events of EUS-guided tissue acquisition (including FNA and FNB) and their prevention}

\section{Recommendation}

EUS-guided tissue acquisition is a safe intervention with relatively low risks of mortality $(0.02 \%)$ and morbidity $(0.98 \%)$. Procedure-related abdominal pain and post-procedure pancreatitis are the most common adverse events. Most unpredictable adverse events are mild in severity and self-limiting, while severe adverse events are very rare (level of evidence: moderate, grade of recommendation: strong).

\section{1) Type and incidence of adverse events}

Wang et al. ${ }^{85}$ reported a systematic review including
51 articles with a total of 10,941 patients who underwent EUS-FNA. According to this systematic review, the overall morbidity rate related to EUS-FNA was $0.98 \%$ $(107 / 10,941)$. Of the 8,246 patients who underwent EUSFNA for pancreatic lesions, including 909 with pancreatic cystic lesions and 7,337 with pancreatic solid tumors, procedure-related adverse events were reported in 85 patients (1.03\%). Of the $36(0.44 \%$ of all patients) patients with pancreatitis, 27 (75.0\%) had mild, six (16.7\%) had moderate, and three $(8.3 \%)$ had severe pancreatitis. Significant bleeding occurred in eight patients ( $0.1 \%$ of all patients). Furthermore, the overall incidence rates of fever and infection were $0.08 \%$, and $0.02 \%$, respectively (Table 6 ). Total procedure-related adverse events were reported in 60 patients $(0.81 \%)$ with solid pancreatic tumors and $25(2.75 \%)$ with pancreatic cyst (Table 6).

\section{2) Specific complications and their prevention \\ (1) Pancreatitis}

Among 4,909 EUS-FNA samples analyzed in a U.S. multicenter survey of solid pancreatic tumors, acute pancreatitis was identified in $14(0.29 \%) .{ }^{86}$ The targeted lesion was located in the head for the majority of the cases $(n=12)$, whereas the lesion was located in the body and tail in one patient each. Furthermore, a recent prospective comparative study ${ }^{87}$ for adverse events due to EUS-guided FNA of pancreatic cystic and solid lesions demonstrated that moderate or higher grade acute pancreatitis occurred in only one patient among 73 patients with pancreatic cystic lesions, while no patients with solid pancreatic lesions were found to have moderate or higher grade acute pancreatitis. Furthermore, two studies demonstrated that hyperamylasemia (defined as a serum amylase concentration above the upper limit of normal without any symptoms) occurred after EUS-guided tissue acquisition of pancreatic lesions. ${ }^{88,89}$ The authors concluded that acute pancreatitis was present in less than $2 \%$ of these patients after EUS-FNA analysis, with silent hyperamylasemia being present in $3 \%$ to $11 \%$. No predictive factor for hyperamylasemia resulting from

Table 6. Procedure-Related Adverse Events from Endoscopic Ultrasound-Guided Tissue Acquisition from Pancreatic Lesions

\begin{tabular}{lccc}
\hline \multicolumn{1}{c}{ Adverse event } & $\begin{array}{c}\text { Overall pancreatic lesions } \\
(\mathrm{n}=8,246)\end{array}$ & $\begin{array}{c}\text { Pancreatic solid tumors } \\
(\mathrm{n}=7,337)\end{array}$ & $\begin{array}{c}\text { Pancreatic cyst } \\
(\mathrm{n}=909)\end{array}$ \\
\hline Abdominal pain & $31(0.38)$ & $24(0.33)$ & $7(0.77)$ \\
Pancreatitis & $36(0.44)$ & $26(0.36)$ & $10(1.10)$ \\
Fever & $7(0.08)$ & $4(0.05)$ & $3(0.33)$ \\
Bleeding & $8(0.10)$ & $5(0.07)$ & $3(0.33)$ \\
Infection & $2(0.02)$ & 0 & $2(0.22)$ \\
Perforation & $1(0.01)$ & $1(0.01)$ & 0 \\
Bile leakage & 0 & 0 & 0 \\
Total & $85(1.03)$ & $60(0.81)$ & $25(2.75)$
\end{tabular}

Data are presented as number (\%). 
EUS-FNA has been identified.

According to multivariate logistic regression risk factor analysis for acute pancreatitis, ${ }^{90}$ there were significant correlations with tumor sizes less than $20 \mathrm{~mm}$ (odds ratio [OR], 18.48; 95\% CI, 3.55 to 96.17) and with PNET (OR, 36.5; 95\% CI, 1.73 to 771.83 ). Therefore, EUS-guided tissue acquisition of small pancreatic masses suspected to be PENTs should also be approached with caution. Although the mechanism is not clear, procedure-related pancreatitis may occur by mechanical injury to the intervening normal pancreatic duct or parenchyma. Therefore, it is reasonable to ensure the shortest distance between the echoendoscope and target lesion when performing sample acquisition to avoid not only the main pancreatic duct but also dilated side branches; in particular, those located upstream from an obstructive mass causing high-pressure build-up of pancreatic juice. The puncture of such a duct may lead to extravasation of pancreatic juice. ${ }^{91}$

\section{(2) Infectious complications}

The incidence of bacteremia or even infection after EUS-guided tissue acquisition is very low, usually insignificant, and similar to that of diagnostic endoscopy including EUS without tissue acquisition. ${ }^{92}$ Furthermore, patients who develop bacteremia after EUS-guided tissue acquisition rarely manifest with a clinical infectious illness. A recent prospective study ${ }^{89}$ found three potential infectious events after EUS-FNA that were self-limited and recovered within a few days using antibiotics. All three cases were pancreatic cystic lesions (total 73 patients) while no patients with solid pancreatic lesions complained of infectious symptoms such as fever. Although all patients received prophylactic antibiotics in this study, there is no strong evidence supporting this clinical practice. Although there is an argument supporting the administration of prophylactic antibiotics in pancreatic cystic lesion, ${ }^{93}$ it only appears to be appropriate when it is impossible to completely aspirate all fluid components.

In conclusion, current guidelines ${ }^{94}$ do not recommend using prophylactic antibiotics in patients undergoing EUSguided tissue acquisition of solid tumors, even in patients at high risk of infective endocarditis because the risk of infection is not higher than other endoscopic interventions. However, endoscopists should consider the RR versus clinical needs for prophylactic antibiotics when target lesions are pure cystic lesions or have partially cystic components. Although there is insufficient evidence to prove the need for prophylactic antibiotics, physicians should consider administering antibiotics whenever the needle penetrates the bile duct, pancreatic duct, or major vascular structure.
(3) Intraluminal or extraluminal bleeding

Intraluminal bleeding following EUS-guided tissue acquisition is typically mild and self-limiting without clinical consequences. Significant bleeding is very rare, but possible if large or major vasculatures are punctured or if patients have a coagulopathy. ${ }^{95}$ In a recent study ${ }^{96}$ using a Japanese nationwide administrative database regarding bleeding after EUS-FNA for pancreatic tumors, seven of 3,090 patients $(0.23 \%)$ required red blood cell transfusion, endoscopic treatment, or angiographic intervention. In addition, three patients $(0.10 \%)$ with severe bleeding required red blood cell transfusion within 3 days after the procedure. However, subgroup analysis revealed that the incidence of severe bleeding in low-volume centers was 5 -fold higher than in medium- and high-volume centers $(p=0.045)$. Despite the lower incidence of intraluminal bleeding related to EUS-guided tissue acquisition, it can be easily controlled with local adrenaline injection or hemostatic clips. ${ }^{97}$

Extra-luminal bleeding manifests as visibly expanding echo-poor regions near the target area, or confirmation of blood flow under color-Doppler ultrasonography, and has been reported to occur in $1.3 \%$ to $2.6 \%$ of all cases. ${ }^{98}$ In addition, intra-cystic bleeding manifests as small hyperechoic areas that progress gradually over a few minutes, or blood flow within the cyst under color-Doppler ultrasonography, and has been reported to occur in 6\% of EUSFNA procedures for pancreatic cysts. ${ }^{99}$ In this situation, endoscopists should terminate further movement or needle passes immediately, observe the apparent bleeding endosonographically, and administer a short course of antibiotics to prevent infection. ${ }^{99}$ Regarding antithrombotic treatment, EUS-guided tissue acquisition should be avoided in patients taking oral anticoagulants such as thienopyridines (e.g., clopidogrel), but not aspirin or nonsteroidal antiinflammatory drugs according to recently issued American Society for Gastrointestinal Endoscopy (ASGE) and ESGE guidelines. ${ }^{87,100}$ If postponing or stopping antithrombotic therapy is not possible in patients with a high risk of thromboembolic events, consulting cardiologists regarding alternative agents and measurement of the risk-to-benefit ratio should be considered.

\section{(4) Tumor seeding}

Needle tract seeding after EUS-guided tissue acquisition has been considered to be an extremely rare adverse event, ${ }^{101}$ although there has been an increasing number of case reports in recent years. ${ }^{102}$ However, a recent study ${ }^{103}$ of 301 patients who underwent distal pancreatectomy demonstrated that six patients (3.4\%), among the 176 who underwent preoperative EUS-FNA, were diagnosed with 
needle tract seeding. This rate of needle tract seeding is not negligible, although preoperative EUS-guided tissue acquisition from the body or tail of the pancreas has not been shown to have a negative effect on recurrence-free survival of pancreatic cancer patients.

\section{3) Do some technical factors influence the complication} rate?

The relationship between the incidence of adverse events after EUS-guided tissue acquisition and needle size is an important issue. Theoretically, the incidence of adverse events with a larger diameter needle was expected to be higher than that using needles that were smaller in diameter.

\section{Learning EUS-guided tissue acquisition; do we recommend a minimum number of supervised procedures?}

\section{Recommendation}

In regard to EUS, the average trainee has to perform at least 225 EUS examinations with a total of 50 EUSguided tissue acquisition procedures for the achievement of competency in EUS-guided FNA or FNB (level of evidence: low, grade of recommendation: weak).

There is little available evidence regarding the minimal average number of performed procedures required to achieve competency in endoscopy. Several trials ${ }^{104-107}$ have reported the results of learning curves in EUS-FNA for solid pancreatic tumors, which are considered to be more complex than diagnostic EUS. In these trials, all trainees had performed at least 132-300 EUS-FNA procedures with the appropriate number of needle passes according to the ROSE guidelines. The sensitivity for the cytopathological diagnosis of pancreatic malignancy is closely related to the operator's experience, of which 20 to 30 performed procedures can lead to a sensitivity of $80 \% .{ }^{56,108}$

Recent guidelines ${ }^{109}$ regarding the endoscopic training by the ASGE recommend that at least 150 supervised EUS procedures be performed before the assessment of competence. It is further recommended that these 150 cases include a minimum of 50 EUS-FNA, 75 pancreaticobiliary cases, 75 mucosal cancer staging cases, and evaluation of 40 subepithelial lesions. ${ }^{110}$ However, a study concluded that 150 cases might be inadequate for achieving competency and recommended that at least 225 hands-on procedures be performed before competence can be assessed. ${ }^{111}$

A more recent study ${ }^{112}$ demonstrated that the minimum number of procedures that trainees should be offered during their training to achieve competence in the core skills of EUS was approximately 225 cases. For EUSguided tissue acquisition, considerable variations were found between the trainees with respect to the speed of training: ${ }^{113}$ thus, this number should be considered to be the minimum before assessment of competence. A previous study evaluated 300 consecutive EUS-FNA procedures performed by a single endosonographer on solid pancreatic tumors over a 3-year period and reported that the proportion of EUS-FNA procedures that required more than 5 needle passes significantly decreased after 100 additional procedures and that the adverse events rate decreased after 200 additional procedures. ${ }^{104}$

\section{CONCLUSION}

This guideline proposes a standard process for physicians who perform EUS-guided tissue acquisition based on the available evidence at the time of preparation in order to prevent unnecessary or unsuitable medical treatments and to facilitate appropriate and practical recommendations for the tissue confirmation of solid pancreatic tumors. We aim to provide a suitable decision-making framework for the accurate diagnosis and appropriate management of patients with solid pancreatic tumors. This guideline is not intended to establish an absolute standard that physicians should use to manage patients in real clinical settings but aims to assist physicians in making evidence-based judgments for the diagnosis of pancreatic solid tumors. Therefore, this guideline should not be used to support legal judgments, establish a legal standard of care or to encourage, advocate, require, or discourage any particular treatment. EUS-guided tissue acquisition has clearly been established as the first-line procedure for the diagnosis of solid pancreatic tumors and will continue to be improved as further research is conducted.

\section{CONFLICTS OF INTEREST}

C.M.C. is an editorial board member of the journal but did not involve in the peer reviewer selection, evaluation, or decision process of this article. No other potential conflicts of interest relevant to this article were reported.

\section{ACKNOWLEDGEMENTS}

This work was supported By the Korean Society of Gastrointestinal Endoscopy (KSGE) Task Force for Clinical Guideline. Any costs for literature searching, conferences, 
and other statistical activities were covered by a research fund provided by the KSGE.

This guideline is being co-published in Gut and Liver, Clinical Endoscopy, the Korean Journal of Gastroenterology, and the Korean Journal of Pancreas and Biliary Tract.

\section{ORCID}

Moon Jae Chung https://orcid.org/0000-0002-5920-8549 Se Woo Park https://orcid.org/0000-0003-1603-7468 Seong-Hun Kim https://orcid.org/0000-0002-7592-8060 Chang Min Cho https://orcid.org/0000-0002-9903-1282 Jun-Ho Choi https://orcid.org/0000-0002-8792-6249 Eun Kwang Choi https://orcid.org/0000-0002-6376-1849 Tae Hoon Lee https://orcid.org/0000-0002-1826-5643 Eunae Cho https://orcid.org/0000-0001-5668-1907 Jun Kyu Lee https://orcid.org/0000-0002-2694-3598 Tae Jun Song https://orcid.org/0000-0002-6156-8746 Jae Min Lee https://orcid.org/0000-0003-0325-8712 Jun Hyuk Son https://orcid.org/0000-0001-9807-8962 Jin Suk Park https://orcid.org/0000-0002-8011-1995 Chi Hyuk Oh https://orcid.org/0000-0002-4382-5876 Dong-Ah Park https://orcid.org/0000-0001-7225-3152 Jeong-Sik Byeon https://orcid.org/0000-0002-9793-6379 Soo Teik Lee https://orcid.org/0000-0002-0758-1923 Ho Gak Kim https://orcid.org/0000-0003-3365-1662 Hoon Jai Chun https://orcid.org/0000-0002-5539-361X Ho Soon Choi https://orcid.org/0000-0003-3746-8742 Chan Guk Park https://orcid.org/0000-0002-9581-2655 Joo Young Cho https://orcid.org/0000-0002-7182-5806

\section{REFERENCES}

1. Vilmann P, Jacobsen GK, Henriksen FW, Hancke S. Endoscopic ultrasonography with guided fine needle aspiration biopsy in pancreatic disease. Gastrointest Endosc 1992;38:172-173.

2. Eisen GM, Chutkan R, Goldstein JL, et al. Role of endoscopic ultrasonography. Gastrointest Endosc 2000;52(6 Pt 1):852859.

3. Maluf-Filho F, Dotti CM, Halwan B, et al. An evidencebased consensus statement on the role and application of endosonography in clinical practice. Endoscopy 2009;41:979987.

4. Kida M. Pancreatic masses. Gastrointest Endosc 2009;69(2 Suppl):S102-S109.

5. Park SW, Chung MJ, Lee SH, et al. Prospective study for comparison of endoscopic ultrasound-guided tissue acquisition using 25- and 22-gauge core biopsy needles in solid pancreatic masses. PLoS One 2016;11:e0154401.

6. Cumpston M, Li T, Page MJ, et al. Updated guidance for trusted systematic reviews: a new edition of the Cochrane Handbook for Systematic Reviews of Interventions. Cochrane Database Syst Rev 2019;10:ED000142.

7. Sterne JA, Savović J, Page MJ, et al. RoB 2: a revised tool for assessing risk of bias in randomized trials. BMJ 2019;366:14898.

8. Stang A. Critical evaluation of the Newcastle-Ottawa scale for the assessment of the quality of nonrandomized studies in meta-analyses. Eur J Epidemiol 2010;25:603-605.

9. Whiting PF, Rutjes AW, Westwood ME, et al. QUADAS-2: a revised tool for the quality assessment of diagnostic accuracy studies. Ann Intern Med 2011;155:529-536.

10. Yokoe M, Takada T, Mayumi T, et al. Japanese guidelines for the management of acute pancreatitis: Japanese Guidelines 2015. J Hepatobiliary Pancreat Sci 2015;22:405-432.

11. Park SK, Ye BD, Kim KO, et al. Guidelines for video capsule endoscopy: emphasis on Crohn's disease. Clin Endosc 2015;48:128-135.

12. Dumonceau JM, Polkowski M, Larghi A, et al. Indications, results, and clinical impact of endoscopic ultrasound (EUS)guided sampling in gastroenterology: European Society of Gastrointestinal Endoscopy (ESGE) Clinical Guideline. Endoscopy 2011;43:897-912.

13. Hébert-Magee S, Bae S, Varadarajulu S, et al. The presence of a cytopathologist increases the diagnostic accuracy of endoscopic ultrasound-guided fine needle aspiration cytology for pancreatic adenocarcinoma: a meta-analysis. Cytopathology 2013;24:159-171.

14. Hewitt MJ, McPhail MJ, Possamai L, Dhar A, Vlavianos P, Monahan KJ. EUS-guided FNA for diagnosis of solid pancreatic neoplasms: a meta-analysis. Gastrointest Endosc 2012;75:319-331.

15. Puli SR, Bechtold ML, Buxbaum JL, Eloubeidi MA. How good is endoscopic ultrasound-guided fine-needle aspiration in diagnosing the correct etiology for a solid pancreatic mass? A meta-analysis and systematic review. Pancreas 2013;42:20-26.

16. Micames C, Jowell PS, White R, et al. Lower frequency of peritoneal carcinomatosis in patients with pancreatic cancer diagnosed by EUS-guided FNA vs. percutaneous FNA. Gastrointest Endosc 2003;58:690-695.

17. van Gulik TM, Reeders JW, Bosma A, et al. Incidence and clinical findings of benign, inflammatory disease in patients resected for presumed pancreatic head cancer. Gastrointest Endosc 1997;46:417-423.

18. Ang TL, Kwek AB, Seo DW, et al. A prospective randomized study of the difference in diagnostic yield between endoscopic ultrasound-guided fine-needle aspiration (EUSFNA) needles with and without a side port in pancreatic masses. 
Endosc Int Open 2015;3:E329-E333.

19. Facciorusso A, Wani S, Triantafyllou K, et al. Comparative accuracy of needle sizes and designs for EUS tissue sampling of solid pancreatic masses: a network meta-analysis. Gastrointest Endosc 2019;90:893-903.

20. Kamata K, Kitano M, Yasukawa S, et al. Histologic diagnosis of pancreatic masses using 25-gauge endoscopic ultrasound needles with and without a core trap: a multicenter randomized trial. Endoscopy 2016;48:632-638.

21. Erickson RA, Sayage-Rabie L, Beissner RS. Factors predicting the number of EUS-guided fine-needle passes for diagnosis of pancreatic malignancies. Gastrointest Endosc 2000;51:184-190.

22. LeBlanc JK, Ciaccia D, Al-Assi MT, et al. Optimal number of EUS-guided fine needle passes needed to obtain a correct diagnosis. Gastrointest Endosc 2004;59:475-481.

23. Bang JY, Hebert-Magee S, Trevino J, Ramesh J, Varadarajulu $\mathrm{S}$. Randomized trial comparing the 22-gauge aspiration and 22-gauge biopsy needles for EUS-guided sampling of solid pancreatic mass lesions. Gastrointest Endosc 2012;76:321327.

24. Bang JY, Magee SH, Ramesh J, Trevino JM, Varadarajulu S. Randomized trial comparing fanning with standard technique for endoscopic ultrasound-guided fine-needle aspiration of solid pancreatic mass lesions. Endoscopy 2013;45:445-450.

25. Möller K, Papanikolaou IS, Toermer T, et al. EUS-guided FNA of solid pancreatic masses: high yield of 2 passes with combined histologic-cytologic analysis. Gastrointest Endosc 2009;70:60-69.

26. Pitman MB, Centeno BA, Ali SZ, et al. Standardized terminology and nomenclature for pancreatobiliary cytology: the Papanicolaou Society of Cytopathology Guidelines. Cytojournal 2014;11(Suppl 1):3.

27. Kliment M, Urban O, Cegan M, et al. Endoscopic ultrasound-guided fine needle aspiration of pancreatic masses: the utility and impact on management of patients. Scand J Gastroenterol 2010;45:1372-1379.

28. Horwhat JD, Paulson EK, McGrath K, et al. A randomized comparison of EUS-guided FNA versus CT or US-guided FNA for the evaluation of pancreatic mass lesions. Gastrointest Endosc 2006;63:966-975.

29. Eloubeidi MA, Varadarajulu S, Desai S, Wilcox CM. Value of repeat endoscopic ultrasound-guided fine needle aspiration for suspected pancreatic cancer. J Gastroenterol Hepatol 2008;23:567-570.

30. Layfield LJ, Schmidt RL, Hirschowitz SL, Olson MT, Ali SZ, Dodd LL. Significance of the diagnostic categories "atypical" and "suspicious for malignancy" in the cytologic diagnosis of solid pancreatic masses. Diagn Cytopathol 2014;42:292-296.

31. Fuccio L, Hassan C, Laterza L, et al. The role of K-ras gene mutation analysis in EUS-guided FNA cytology specimens for the differential diagnosis of pancreatic solid masses: a meta-analysis of prospective studies. Gastrointest Endosc 2013;78:596-608.

32. Iglesias-Garcia J, Dominguez-Munoz JE, Abdulkader I, et al. Influence of on-site cytopathology evaluation on the diagnostic accuracy of endoscopic ultrasound-guided fine needle aspiration (EUS-FNA) of solid pancreatic masses. Am J Gastroenterol 2011;106:1705-1710.

33. Wani S, Mullady D, Early DS, et al. The clinical impact of immediate on-site cytopathology evaluation during endoscopic ultrasound-guided fine needle aspiration of pancreatic masses: a prospective multicenter randomized controlled trial. Am J Gastroenterol 2015;110:1429-1439.

34. Ganc RL, Carbonari AP, Colaiacovo R, et al. Rapid on-site cytopathological examination (ROSE) performed by endosonagraphers and its improvement in the diagnosis of pancreatic solid lesions. Acta Cir Bras 2015;30:503-508.

35. Cermak TS, Wang B, DeBrito P, Carroll J, Haddad N, Sidawy MK. Does on-site adequacy evaluation reduce the nondiagnostic rate in endoscopic ultrasound-guided fineneedle aspiration of pancreatic lesions? Cancer Cytopathol 2012;120:319-325.

36. Kong F, Zhu J, Kong X, et al. Rapid on-site evaluation does not improve endoscopic ultrasound-guided fine needle aspiration adequacy in pancreatic masses: a meta-analysis and systematic review. PLoS One 2016;11:e0163056.

37. Matynia AP, Schmidt RL, Barraza G, Layfield LJ, Siddiqui AA, Adler DG. Impact of rapid on-site evaluation on the adequacy of endoscopic-ultrasound guided fine-needle aspiration of solid pancreatic lesions: a systematic review and meta-analysis. J Gastroenterol Hepatol 2014;29:697-705.

38. Kim JH, Park SW, Kim MK, et al. Meta-analysis for cytopathological outcomes in endoscopic ultrasonographyguided fine-needle aspiration with and without the stylet. Dig Dis Sci 2016;61:2175-2184.

39. Sahai AV, Paquin SC, Gariépy G. A prospective comparison of endoscopic ultrasound-guided fine needle aspiration results obtained in the same lesion, with and without the needle stylet. Endoscopy 2010;42:900-903.

40. Wani S, Early D, Kunkel J, et al. Diagnostic yield of malignancy during EUS-guided FNA of solid lesions with and without a stylet: a prospective, single blind, randomized, controlled trial. Gastrointest Endosc 2012;76:328-335.

41. Puri R, Vilmann P, Săftoiu A, et al. Randomized controlled trial of endoscopic ultrasound-guided fine-needle sampling with or without suction for better cytological diagnosis. Scand J Gastroenterol 2009;44:499-504.

42. Lee JK, Choi JH, Lee $\mathrm{KH}$, et al. A prospective, comparative trial to optimize sampling techniques in EUS-guided FNA of solid pancreatic masses. Gastrointest Endosc 2013;77:745- 
751.

43. Kudo T, Kawakami H, Hayashi T, et al. High and low negative pressure suction techniques in EUS-guided fine-needle tissue acquisition by using 25-gauge needles: a multicenter, prospective, randomized, controlled trial. Gastrointest Endosc 2014;80:1030-1037.

44. Nakai Y, Isayama $H$, Chang KJ, et al. Slow pull versus suction in endoscopic ultrasound-guided fine-needle aspiration of pancreatic solid masses. Dig Dis Sci 2014;59:1578-1585.

45. Matsubayashi H, Matsui T, Yabuuchi Y, et al. Endoscopic ultrasonography guided-fine needle aspiration for the diagnosis of solid pancreaticobiliary lesions: clinical aspects to improve the diagnosis. World J Gastroenterol 2016;22:628640.

46. Lee KY, Cho HD, Hwangbo Y, et al. Efficacy of 3 fine-needle biopsy techniques for suspected pancreatic malignancies in the absence of an on-site cytopathologist. Gastrointest Endosc 2019;89:825-831.

47. Bor R, Vasas B, Fábián A, et al. Prospective comparison of slow-pull and standard suction techniques of endoscopic ultrasound-guided fine needle aspiration in the diagnosis of solid pancreatic cancer. BMC Gastroenterol 2019;19:6.

48. Park SW, Lee SS, Song TJ, et al. The diagnostic performance of novel torque technique for endoscopic ultrasound-guided tissue acquisition in solid pancreatic lesions: a prospective randomized controlled trial. J Gastroenterol Hepatol 2020;35:508-515.

49. Matsubayashi H, Sasaki K, Ono S, et al. Pathological and molecular aspects to improve endoscopic ultrasonographyguided fine-needle aspiration from solid pancreatic lesions. Pancreas 2018;47:163-172.

50. Kocjan G, Chandra A, Cross P, et al. BSCC Code of Practice: fine needle aspiration cytology. Cytopathology 2009;20:283296.

51. Thierry R, Marie-Christine R, Marièle M, Richard B, Anca M. Modified technique of toluidine blue staining in rapid on-site evaluation. Diagn Cytopathol 2012;40:847-848.

52. Lee YN, Moon JH, Kim HK, et al. A triple approach for diagnostic assessment of endoscopic ultrasound-guided fine needle aspiration in pancreatic solid masses and lymph nodes. Dig Dis Sci 2014;59:2286-2293.

53. Arbyn M, Bergeron C, Klinkhamer P, Martin-Hirsch P, Siebers AG, Bulten J. Liquid compared with conventional cervical cytology: a systematic review and meta-analysis. Obstet Gynecol 2008;111:167-177.

54. Siddiqui MT, Gokaslan ST, Saboorian MH, Ashfaq R. Split sample comparison of ThinPrep and conventional smears in endoscopic retrograde cholangiopancreatographyguided pancreatic fine-needle aspirations. Diagn Cytopathol 2005;32:70-75

55. Qin SY, Zhou Y, Li P, Jiang HX. Diagnostic efficacy of cell block immunohistochemistry, smear cytology, and liquidbased cytology in endoscopic ultrasound-guided fine-needle aspiration of pancreatic lesions: a single-institution experience. PLoS One 2014;9:e108762.

56. LeBlanc JK, Emerson RE, Dewitt J, et al. A prospective study comparing rapid assessment of smears and ThinPrep for endoscopic ultrasound-guided fine-needle aspirates. Endoscopy 2010;42:389-394.

57. Lee JK, Choi ER, Jang TH, et al. A prospective comparison of liquid-based cytology and traditional smear cytology in pancreatic endoscopic ultrasound-guided fine needle aspiration. Acta Cytol 2011;55:401-407.

58. Lee KJ, Kang YS, Cho MY, Kim JW. Comparison of cytologic preparation methods in endoscopic ultrasound-guided fine needle aspiration for diagnosis of pancreatic adenocarcinoma. Pancreatology 2016;16:824-828.

59. Ieni A, Barresi V, Todaro P, Caruso RA, Tuccari G. Cellblock procedure in endoscopic ultrasound-guided-fineneedle-aspiration of gastrointestinal solid neoplastic lesions. World J Gastrointest Endosc 2015;7:1014-1022.

60. Noda Y, Fujita N, Kobayashi G, et al. Diagnostic efficacy of the cell block method in comparison with smear cytology of tissue samples obtained by endoscopic ultrasound-guided fine-needle aspiration. J Gastroenterol 2010;45:868-875.

61. Rusch M, Nakitandwe J, Shurtleff S, et al. Clinical cancer genomic profiling by three-platform sequencing of whole genome, whole exome and transcriptome. Nat Commun 2018;9:3962.

62. Gao L, Antic T, Hyjek E, et al. Immunohistochemical analysis of E-cadherin and zeste homolog 2 expression in endoscopic ultrasound-guided fine-needle aspiration of pancreatic adenocarcinoma. Cancer Cytopathol 2013;121:644-652.

63. Dim DC, Jiang F, Qiu Q, et al. The usefulness of S100P, mesothelin, fascin, prostate stem cell antigen, and 14-3-3 sigma in diagnosing pancreatic adenocarcinoma in cytological specimens obtained by endoscopic ultrasound guided fineneedle aspiration. Diagn Cytopathol 2014;42:193-199.

64. Hasegawa T, Yamao K, Hijioka S, et al. Evaluation of Ki-67 index in EUS-FNA specimens for the assessment of malignancy risk in pancreatic neuroendocrine tumors. Endoscopy 2014;46:32-38.

65. O'Brien MJ, Takahashi M, Brugal G, et al. Digital imagery/ telecytology. International Academy of Cytology Task Force summary. Diagnostic Cytology Towards the 21st Century: An International Expert Conference and Tutorial. Acta Cytol 1998;42:148-164.

66. Kim B, Chhieng DC, Crowe DR, et al. Dynamic telecytopathology of on site rapid cytology diagnoses for pancreatic carcinoma. Cytojournal 2006;3:27.

67. Nasuti JF, Gupta PK, Baloch ZW. Diagnostic value and costeffectiveness of on-site evaluation of fine-needle aspira- 
tion specimens: review of 5,688 cases. Diagn Cytopathol 2002;27:1-4.

68. Alsharif M, Carlo-Demovich J, Massey C, et al. Telecytopathology for immediate evaluation of fine-needle aspiration specimens. Cancer Cytopathol 2010;118:119-126.

69. Marotti JD, Johncox V, Ng D, Gonzalez JL, Padmanabhan V. Implementation of telecytology for immediate assessment of endoscopic ultrasound-guided fine-needle aspirations compared to conventional on-site evaluation: analysis of 240 consecutive cases. Acta Cytol 2012;56:548-553.

70. Brosens LA, Hackeng WM, Offerhaus GJ, Hruban RH, Wood LD. Pancreatic adenocarcinoma pathology: changing "landscape". J Gastrointest Oncol 2015;6:358-374.

71. Matsubayashi H, Watanabe H, Ajioka Y, et al. Different amounts of K-ras mutant epithelial cells in pancreatic carcinoma and mass-forming pancreatitis. Pancreas 2000;21:7785.

72. Kleeff J, Korc M, Apte M, et al. Pancreatic cancer. Nat Rev Dis Primers 2016;2:16022.

73. Levy MJ, Oberg TN, Campion MB, et al. Comparison of methods to detect neoplasia in patients undergoing endoscopic ultrasound-guided fine-needle aspiration. Gastroenterology 2012;142:1112-1121.

74. Ribeiro A, Peng J, Casas C, Fan YS. Endoscopic ultrasound guided fine needle aspiration with fluorescence in situ hybridization analysis in 104 patients with pancreatic mass. J Gastroenterol Hepatol 2014;29:1654-1658.

75. Koorstra JB, Hustinx SR, Offerhaus GJ, Maitra A. Pancreatic carcinogenesis. Pancreatology 2008;8:110-125.

76. Jhala NC, Eltoum IA, Eloubeidi MA, et al. Providing on-site diagnosis of malignancy on endoscopic-ultrasound-guided fine-needle aspirates: should it be done? Ann Diagn Pathol 2007;11:176-181.

77. Oshima M, Okano K, Muraki S, et al. Immunohistochemically detected expression of 3 major genes (CDKN2A/ p16, TP53, and SMAD4/DPC4) strongly predicts survival in patients with resectable pancreatic cancer. Ann Surg 2013;258:336-346.

78. Lee J, Jang KT, Ki CS, et al. Impact of epidermal growth factor receptor (EGFR) kinase mutations, EGFR gene amplifications, and KRAS mutations on survival of pancreatic adenocarcinoma. Cancer 2007;109:1561-1569.

79. Kobayashi M, Mizuno S, Murata Y, et al. Gemcitabine-based chemoradiotherapy followed by surgery for borderline resectable and locally unresectable pancreatic ductal adenocarcinoma: significance of the CA19-9 reduction rate and intratumoral human equilibrative nucleoside transporter 1 expression. Pancreas 2014;43:350-360.

80. Fujita H, Ohuchida K, Mizumoto K, et al. High EGFR mRNA expression is a prognostic factor for reduced survival in pancreatic cancer after gemcitabine-based adjuvant che- motherapy. Int J Oncol 2011;38:629-641.

81. Ma G, Sun Y, Fu S. Evaluation of S100A4 mRNA in EUSFNA specimens for the assessment of chemosensitivity to gemcitabine from patients with unresectable pancreatic cancer. Int J Clin Exp Pathol 2015;8:13284-13288.

82. Preis M, Gardner TB, Gordon SR, et al. MicroRNA-10b expression correlates with response to neoadjuvant therapy and survival in pancreatic ductal adenocarcinoma. Clin Cancer Res 2011;17:5812-5821.

83. Duconseil P, Gilabert M, Gayet O, et al. Transcriptomic analysis predicts survival and sensitivity to anticancer drugs of patients with a pancreatic adenocarcinoma. Am J Pathol 2015;185:1022-1032.

84. Wakatsuki T, Irisawa A, Imamura $\mathrm{H}$, et al. Complete response of anaplastic pancreatic carcinoma to paclitaxel treatment selected by chemosensitivity testing. Int J Clin Oncol 2010;15:310-313.

85. Wang KX, Ben QW, Jin ZD, et al. Assessment of morbidity and mortality associated with EUS-guided FNA: a systematic review. Gastrointest Endosc 2011;73:283-290.

86. Eloubeidi MA, Gress FG, Savides TJ, et al. Acute pancreatitis after EUS-guided FNA of solid pancreatic masses: a pooled analysis from EUS centers in the United States. Gastrointest Endosc 2004;60:385-389.

87. Rodríguez-D'Jesús A, Fernández-Esparrach G, Marra-Lopez $C$, et al. Adverse events of EUS-guided FNA of pancreatic cystic and solid lesions by using the lexicon proposed in an ASGE workshop: a prospective and comparative study. Gastrointest Endosc 2016;83:780-784.

88. Fernández-Esparrach G, Ginès A, García P, et al. Incidence and clinical significance of hyperamylasemia after endoscopic ultrasound-guided fine-needle aspiration (EUS-FNA) of pancreatic lesions: a prospective and controlled study. Endoscopy 2007;39:720-724.

89. Gress FG, Barawi M, Kim D, Grendell JH. Preoperative localization of a neuroendocrine tumor of the pancreas with EUS-guided fine needle tattooing. Gastrointest Endosc 2002;55:594-597.

90. Katanuma A, Maguchi H, Yane K, et al. Factors predictive of adverse events associated with endoscopic ultrasoundguided fine needle aspiration of pancreatic solid lesions. Dig Dis Sci 2013;58:2093-2099.

91. Fujii LL, Levy MJ. Basic techniques in endoscopic ultrasound-guided fine needle aspiration for solid lesions: adverse events and avoiding them. Endosc Ultrasound 2014;3:35-45.

92. Janssen J, König K, Knop-Hammad V, Johanns W, Greiner L. Frequency of bacteremia after linear EUS of the upper GI tract with and without FNA. Gastrointest Endosc 2004;59:339-344.

93. Guarner-Argente C, Shah P, Buchner A, Ahmad NA, Kochman ML, Ginsberg GG. Use of antimicrobials for EUS- 
guided FNA of pancreatic cysts: a retrospective, comparative analysis. Gastrointest Endosc 2011;74:81-86.

94. ASGE Standards of Practice Committee, Banerjee S, Shen B, et al. Antibiotic prophylaxis for GI endoscopy. Gastrointest Endosc 2008;67:791-798.

95. Polkowski M, Larghi A, Weynand B, et al. Learning, techniques, and complications of endoscopic ultrasound (EUS)guided sampling in gastroenterology: European Society of Gastrointestinal Endoscopy (ESGE) Technical Guideline. Endoscopy 2012;44:190-206.

96. Hamada T, Yasunaga H, Nakai Y, et al. Severe bleeding and perforation are rare complications of endoscopic ultrasound-guided fine needle aspiration for pancreatic masses: an analysis of 3,090 patients from 212 hospitals. Gut Liver 2014;8:215-218.

97. Dumonceau JM, Deprez PH, Jenssen C, et al. Indications, results, and clinical impact of endoscopic ultrasound (EUS)guided sampling in gastroenterology: European Society of Gastrointestinal Endoscopy (ESGE) Clinical Guideline: updated January 2017. Endoscopy 2017;49:695-714.

98. Affi A, Vazquez-Sequeiros E, Norton ID, Clain JE, Wiersema MJ. Acute extraluminal hemorrhage associated with EUSguided fine needle aspiration: frequency and clinical significance. Gastrointest Endosc 2001;53:221-225.

99. Varadarajulu S, Eloubeidi MA. Frequency and significance of acute intracystic hemorrhage during EUS-FNA of cystic lesions of the pancreas. Gastrointest Endosc 2004;60:631635.

100. Veitch AM, Vanbiervliet G, Gershlick AH, et al. Endoscopy in patients on antiplatelet or anticoagulant therapy, including direct oral anticoagulants: British Society of Gastroenterology (BSG) and European Society of Gastrointestinal Endoscopy (ESGE) guidelines. Gut 2016;65:374-389.

101. ASGE Standards of Practice Committee, Eloubeidi MA, Decker GA, et al. The role of endoscopy in the evaluation and management of patients with solid pancreatic neoplasia. Gastrointest Endosc 2016;83:17-28.

102. Minaga K, Kitano M, Enoki E, Kashida H, Kudo M. Needletract seeding on the proximal gastric wall after EUS-guided fine-needle aspiration of a pancreatic mass. Am J Gastroenterol 2016;111:1515.
103. Yane K, Kuwatani M, Yoshida M, et al. Non-negligible rate of needle tract seeding after endoscopic ultrasound-guided fine-needle aspiration for patients undergoing distal pancreatectomy for pancreatic cancer. Dig Endosc 2020;32:801811.

104. Eloubeidi MA, Tamhane A. EUS-guided FNA of solid pancreatic masses: a learning curve with 300 consecutive procedures. Gastrointest Endosc 2005;61:700-708.

105. Mertz H, Gautam S. The learning curve for EUS-guided FNA of pancreatic cancer. Gastrointest Endosc 2004;59:3337.

106. Harewood GC, Wiersema LM, Halling AC, Keeney GL, Salamao DR, Wiersema MJ. Influence of EUS training and pathology interpretation on accuracy of EUS-guided fine needle aspiration of pancreatic masses. Gastrointest Endosc 2002;55:669-673.

107. Eisen GM, Dominitz JA, Faigel DO, et al. Guidelines for credentialing and granting privileges for endoscopic ultrasound. Gastrointest Endosc 2001;54:811-814.

108. Klapman JB, Logrono R, Dye CE, Waxman I. Clinical impact of on-site cytopathology interpretation on endoscopic ultrasound-guided fine needle aspiration. Am J Gastroenterol 2003;98:1289-1294.

109. ASGE Standards of Practice Committee, Faulx AL, Lightdale JR, et al. Guidelines for privileging, credentialing, and proctoring to perform GI endoscopy. Gastrointest Endosc 2017;85:273-281.

110. ASGE Training Committee, DiMaio CJ, Mishra G, et al. EUS core curriculum. Gastrointest Endosc 2012;76:476-481.

111. Wani S, Coté GA, Keswani R, et al. Learning curves for EUS by using cumulative sum analysis: implications for American Society for Gastrointestinal Endoscopy recommendations for training. Gastrointest Endosc 2013;77:558-565.

112. Wani S, Han S, Simon V, et al. Setting minimum standards for training in EUS and ERCP: results from a prospective multicenter study evaluating learning curves and competence among advanced endoscopy trainees. Gastrointest Endosc 2019;89:1160-1168.

113. Sarker SK, Albrani T, Zaman A, Kumar I. Procedural performance in gastrointestinal endoscopy: live and simulated. World J Surg 2010;34:1764-1770. 